\title{
Science Mapping Approach to Assisting the Review of Construction and Demolition Waste Management Research Published between 2009 and 2018
}

\author{
Ruoyu Jin ${ }^{\mathrm{a}, *}$, Hongping Yuan ${ }^{\mathrm{b}}$, Qian Chen ${ }^{\mathrm{c}}$ \\ a Senior Lecturer, School of Environment and Technology, University of Brighton, Cockcroft Building 616, \\ Brighton, UK. Email: R.Jin@brighton.ac.uk \\ bProfessor, School of Management, Guangzhou University, Guangdong, 510006, P.R. China. Email: \\ hpyuan2005@gmail.com
}

cAssociate Professor, Department of Food, Agricultural, and Biological Engineering, The Ohio State University, 590 Woody Hayes Dr., Columbus, OH 43210, U.S.A. E-mail: chen.1399@osu.edu

\begin{abstract}
Sustainable treatments of construction and demolition (C\&D) wastes have become an increasingly urgent social, environmental, and economic issue worldwide. Based on a filter of 370 articles related to $C \& D$ waste management, this review-based study adopted a science mapping approach to evaluating the recent decade’s $C \& D$ waste management research. Through a three-step workflow consisting of bibliometric literature search, scientometric analysis, and qualitative discussion, this study identified the most influential journals, scholars, articles, and countries that have been active and influential in the C\&D waste management research since 2009. Keyword analysis revealed the emerging research topics, such as BIM, prefabricated construction, Big Data, and Circular Economy. The follow-up discussion summarized the mainstream research areas (e.g., qualification of waste generation), discussed research gaps (e.g., integration of BIM and Big Data into C\&D waste management), and proposed the framework for near-future research, such as a comprehensive evaluation of the performance of C\&D waste diversion, human factors, and design and planning for waste diversion. By providing the big picture of the latest research in C\&D waste management since
\end{abstract}


2009, the paper serves as a multi-disciplinary guide for practitioners and researchers to link current research areas into future trends.

Keywords: Construction and demolition waste; sustainable development; science mapping; waste management; scientometric analysis; literature review.

\section{Introduction}

Construction and demolition (C\&D) wastes refer to a mixture of surplus materials generated from construction, renovation, and demolition activities including site clearance, roadwork, and demolition (Shen et al., 2004). C\&D wastes may consist of different sources such as asphalt, concrete, and wood (Poulikakos et al., 2017). C\&D wastes account for 30\% to $40 \%$ of the total solid wastes (C\&D Waste Management Guide, 2016; European Commission, 2011; Rodríguez-Robles et al., 2015). The increasing amount of C\&D waste materials due to urbanization and related $C \& D$ activities are causing negative impacts on the environment and society (Lu and Yuan, 2010; Meng et al., 2018). In many parts of the world, disposing of C\&D wastes to landfills without recycling remains the commonplace treatment method (Duan and Li, 2016). Iillegal dumping still happens (Seror and Portnov, 2018). Due to the limited landfill spaces, water pollution, energy consumption, and harmful gas emissions, wastes from building demolition have become a major challenge to sustainable urban development (Ding et al., 2016). The urgency of reducing, reusing and recycling $C \& D$ wastes in order to release the pressure of landfills and to enhance the waste diversion practice has driven the sustainability movement from both governmental and industry perspectives (Jin et al., 2017). According to multiple previous studies (Jin et al., 2017; Marrero et al., 2017; Mastrucci et al., 2017), C\&D waste management is an inter-disciplinary theme involving social, environmental, and economic aspects, and simultaneously it covers complicated issues from the engineering, technological, management, and policy perspectives. Thus, a comprehensive review of the 
state-of-the-art C\&D waste management research would be useful to provide a holistic picture to multiple stakeholders including practitioners, researchers, and authorities.

An early research by Yuan and Shen (2011) predicted that C\&D waste management would become an emerging research and practical issue in developing countries. (Li et al., 2018b) performed bibliometric analysis for solid waste reuse and recycling, and further identified the gap of C\&D waste management between developing and developed countries. Although C\&D waste management is considered a key issue in terms of their contribution to Circular Economy (Li et al., 2018b; Mahpour, 2018; Miatto et al., 2017), there has been insufficient review of C\&D waste management research in the recent decade to follow up the study conducted by (Yuan and Shen, 2011). Although there have been multiple review-based studies in the domain of $C \& D$ waste treatment, these studies were either limited to $C \& D$ recycling technical perspective (Chen et al., 2016; Evangelista and De Brito, 2014; Umar et al., 2017) or not covering the state-of-the-art C\&D waste treatment practice (Brasileiro and Matos, 2015; Menegaki and Damigos, 2018). The fast movement of contemporary construction issues, including digital construction such as BIM (i.e., Building Information Modeling), prefabricated construction, and sustainability have been applied in C\&D waste management, such as BIM in waste minimization (Won and Cheng, 2017), Big Data approach in waste generation estimate (Lu et al., 2016), prefabrication approach in reducing waste (Li et al., 2014), and incorporating the concept of Circular Economy into C\&D waste diversion (Esa et al., 2017a). There is a need to look into the applications of emerging technologies or approaches in C\&D waste management, as well as to investigate the potential of integrating these technologies/approaches to enhance the C\&D waste diversion practices especially in the recent decade.

Literature review is an expedient approach to gain an in-depth understanding of a research domain (He et al., 2017). The limitations of some existing review-based studies (Ke et al., 2009; 
Tang et al., 2010) in the field of construction engineering and project management are that they relied on subjective judgements which might be biased or even misguiding (Hosseini et al., 2018; Song et al., 2016). For example, in these existing review-based studies (Martínez-Aires et al., 2018), only articles from journals that the scholars perceived influential were included for literature review. Further, these review-based studies might have only included a limited literature sample (Martínez-Aires et al., 2018). More definitions of subjective judgements can be found in Hammersley (2001). To minimize these potential subjectivities, studies including Zhao (2017), Li et al. (2018b), and Hosseini et al. (2018) introduced the science mapping approach into the field of construction engineering and management. These existing reviewbased studies have adopted the science mapping approach in studying the mainstream keywords, co-authorship network, citations of journals and articles in the target research theme, such as BIM (Zhao, 2017), off-site construction (Hosseini et al., 2018), building performance analysis (Park and Nagy, 2018), and public-private-partnership (Song et al., 2016). It has been further addressed by Xu et al. (2018) and Jin et al. (2018) that a science mapping approach could be incorporated in a holistic review method by extending it into a follow-up qualitative discussion which could lead to a new research framework guiding future scholarly work. Following these studies, it is believed that a more comprehensive review approach can be adopted by adding a more in-depth discussion assisted by science mapping. For example, the study of Li et al. (2018b), which reviewed solid waste management, could be extended with a further discussion on the research gaps and framework for future research.

The novelty of this research lies in that: 1) it applied the science mapping approach in the research domain of $\mathrm{C} \& \mathrm{D}$ waste management. The science mapping approach, consisting of bibliometric literature search and scientometric analysis (Hosseini et al., 2018), could minimize the subjectivity and biasedness (Song et al., 2016) in performing review-based studies in C\&D waste management (e.g., Brasileiro and Matos, 2015); 2) the research extended the science 
mapping approach in waste management review (e.g., Li et al., 2018b) with an in-depth qualitative discussion, by evaluating the $C \& D$ waste management research in the recent decade with a more holistic approach. The following objectives are targeted: 1) analyzing the main research topics within $C \& D$ waste management; 2) identifying the current research gaps in it; and 3) proposing a framework to guide future research directions. This study serves as a followup evaluation of Yuan and Shen (2011) who discussed the trend of C\&D waste management research based on the review of literature published between 2000 and 2009. The proposed research directions by Yuan and Shen (2011) are revisited leading to further discussions and expectations on both ongoing and newly emerging research topics in C\&D waste management.

The remainder of this paper is structured as follows: Section 2 describes the holistic review methodology incorporating science mapping and a further qualitative discussion; Section 3 presents the results and initial findings through science mapping; Section 4 extends the science mapping approach to discuss the research topics, gaps, and trends in C\&D waste management; and Section 5 concludes this review-based study.

\section{Methodology}

This review-based study adopts a holistic approach to evaluating the latest research outputs (i.e., 2009-2018) in the domain of C\&D waste management published in Scopus. The overall workflow is illustrated in Fig. 1, which contains the science mapping approach consisting of biblimetric search and scientometric analysis, and qualitative discussion. 


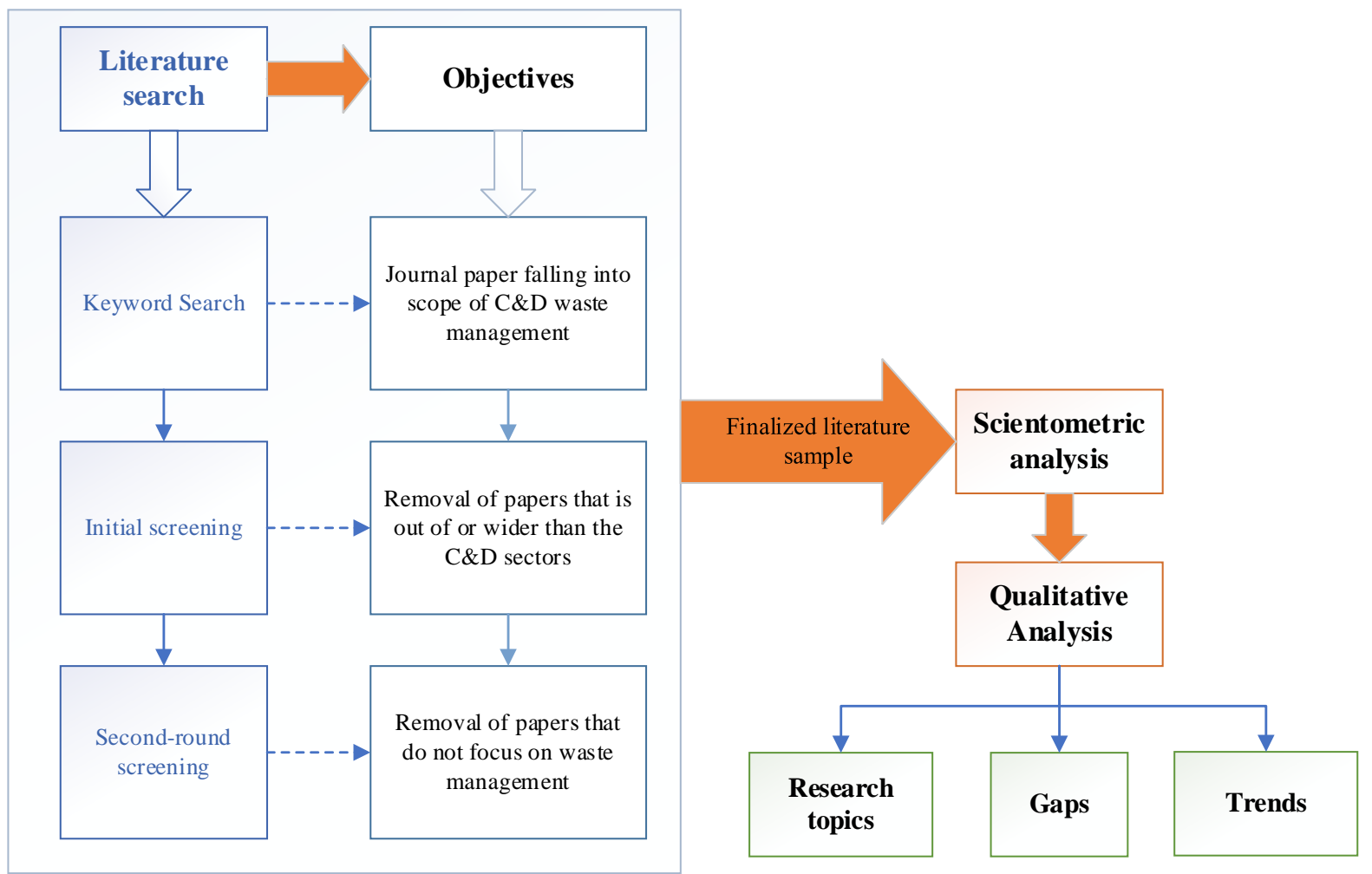

Fig.1. The three-step workflow for reviewing the C\&D waste management literature

\subsection{Bibliometric search}

The bibliometric search of C\&D waste management publications was performed in Scopus, which is one of the main search engines for academic outputs. It is believed that Scopus covers more journals and more recent publications than other digital sources such as Web of Science (Aghaei Chadegani et al., 2013). The literature search started from inputting the following keywords in Scopus:

TITLE-ABS-KEY ("construction and demolition waste" OR "C\&D waste" OR "C\&D wastes" OR "CDW" OR "construction waste" OR "demolition waste"

AND

“waste management”)

The keywords search identified related journal articles published in English during 20092018. Conference papers were excluded due to the fact that they did not provide as much 
information as journal articles do (Butler and Visser, 2006). As shown in Fig. 1, a total of three sub-steps were performed in the bibliometric literature search to screen out articles that are either out of scope or do not focus on C\&D waste management.

\subsection{Science mapping}

VOSViewer, a text-mining tool developed by (van Eck and Waltman, 2010), was adopted in this study for analyzing and visualizing bibliometric networks. According to (Van Eck and Waltman, 2014), VOSViewer provides distance-based visualizations of bibliometric networks. The distance between two nodes approximately indicates the relatedness between them. VOSViewer is suitable for visualizing larger networks. It also has special text mining features. More detailed descriptions of the working mechanism of VOSViewer can be found in Van Eck and Waltman (2014). Some existing studies in the field of construction engineering and project management has adopted VOSViewer to assist the literature review of various topics, such as the public-private-partnership (Song et al., 2016), BIM (He et al., 2017), and building environmental control (Park and Nagy, 2018). This study adopted VOSViewer to achieve the following objectives: 1) to load the downloaded literature sample from Scopus; 2) to visualize, compute, and analyze the influence of key journals, scholars, publications, and countries in the research community of $C \& D$ waste management; and 3) to study the mainstream research keywords and their inter-relationships.

\subsection{Qualitative discussion}

Qualitative discussion was the last step following bibiometric search and scietometric analysis. According to Fig.1, three major objectives were to be achieved in the in-depth qualitative discussion, which include summarizing the currently ongoing main research topics within $C \& D$ waste management, identifying the research limitations or gaps, and proposing future research directions. 


\section{Results of scientometric analysis}

The keyword-based bibliometric search in Scopus produced a list of 410 related journal articles. The initial screening performed by researchers screened out articles that studied waste management out of or extending beyond the C\&D sectors. For example, Fagnani and Guimarães (2017) and Jones et al. (2009), though targeting waste processing and management, did not focus on the C\&D industry. Other studies such as Dong and Lee (2009), Pattnaik and Reddy (2010), as well as Staley and Barlaz (2009) focused on a larger scope (e.g., solid, municipal, or industrial wastes), which covered the C\&D waste but was not limited to it. Hence, these studies were removed from the literature sample. The second-round screening verified the research objectives of the remaining articles. Only those papers that had a focus on waste management would stay. Studies such as Abanda et al. (2013) and Chau et al. (2012), although mentioning recycled materials or material usage, aimed to study other sustainability problems

(e.g., carbon footprint of buildings or embodied energy). These articles were also removed from the sample. Ultimately, 370 articles were included in the review.

\subsection{An overview of the literature sample}

Fig. 2 displays the number of papers published yearly between 2009-2018 in the selected literature sample. The data show the overall trend of research outputs in C\&D waste management in the past decade. Excluding the incomplete data for 2018, generally the annual number of publications has been increasing since 2009, from below 30 total articles published annually in 2009 and 2010 to over 60 in 2016 and 2017. This indicates that the research 
community had increasing interests and outputs in C\&D waste management in recent years.

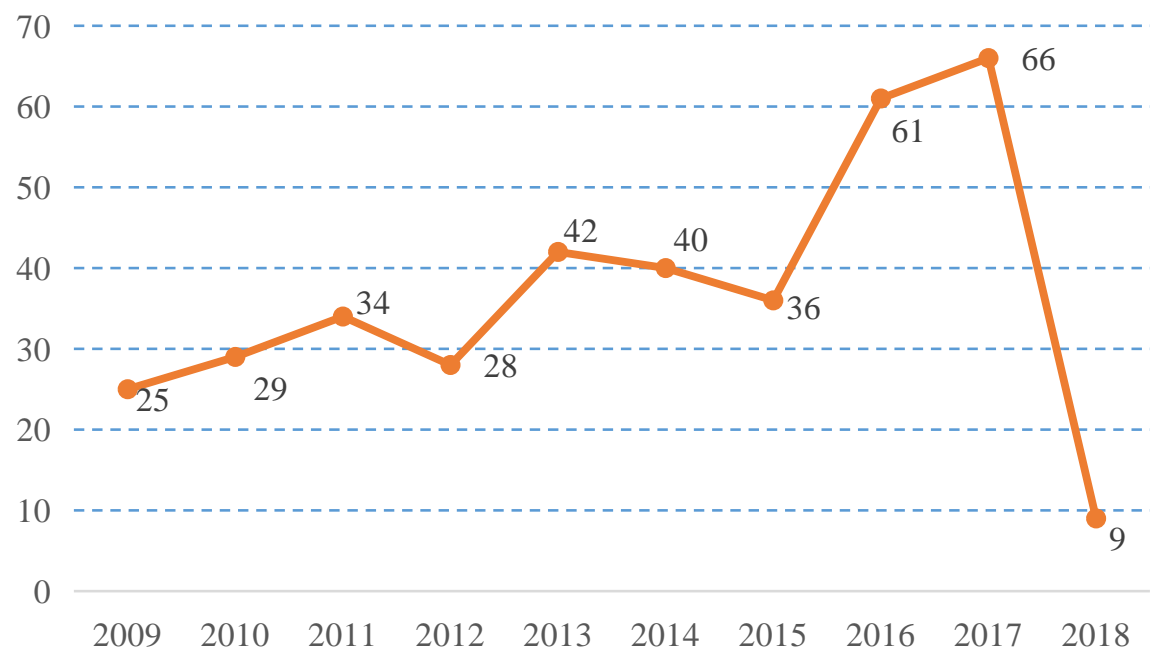

Note: the number of journal papers in 2018 is incomplete and up to the end of February

Fig.2. Yearly publications from 2009 to 2018

\subsection{Science mapping of journal sources}

Source journals, where the selected C\&D waste management journal articles were published, were identified, visualized, and evaluated in this study. The results are shown in Fig. 3 and Table 1. The minimum number of papers published and the minimum number of citations were set at 3 and 30, respectively, in VOSViewer. In total 12 out of 121 journals met the threshold. Fig. 3 displays the clusters of journal sources and their inter-relationships through connection lines. Note that journal names may not be shown fully in VOSViewer. The missing information can be seen in Table 1. 


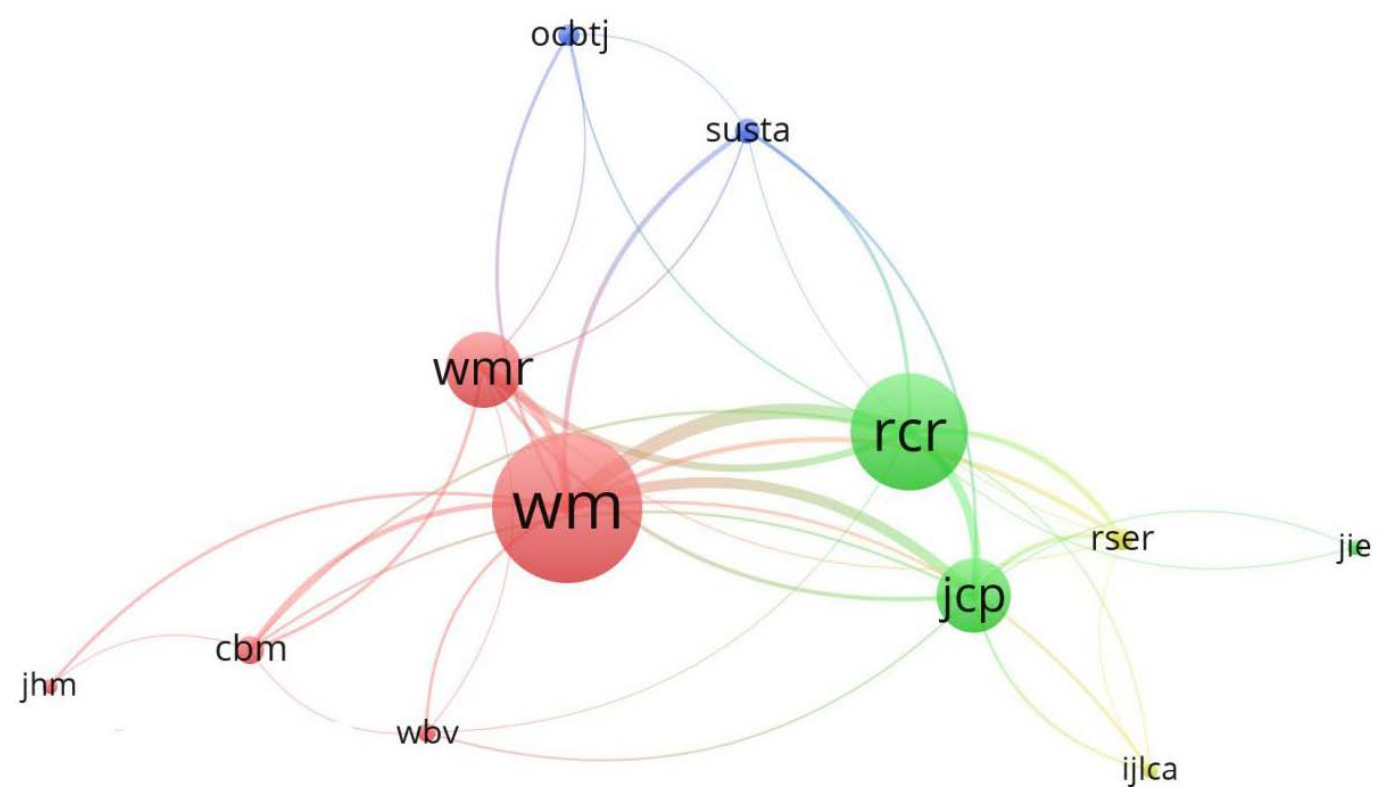

Fig.3. Mapping of mainstream journals in the domain of C\&D waste management

Table 1. Quantitative measurements of journals publishing C\&D waste management research

\begin{tabular}{l|l|c|c|c|c}
\hline $\begin{array}{l}\text { Acronym in } \\
\text { VOSViewer }\end{array}$ & \multicolumn{1}{c|}{ Source } & $\begin{array}{c}\text { Number of } \\
\text { publications }\end{array}$ & $\begin{array}{c}\text { Total } \\
\text { citations }\end{array}$ & $\begin{array}{c}\text { Average } \\
\text { citations }\end{array}$ & $\begin{array}{c}\text { Avorm. } \\
\text { Citation }\end{array}$ \\
\hline$W M$ & Waste Management & 65 & 1843 & 28 & 1.6 \\
\hline$R C R$ & $\begin{array}{l}\text { Resources, Conservation } \\
\text { and Recycling }\end{array}$ & 48 & 1094 & 23 & 1.8 \\
\hline$W M R$ & $\begin{array}{l}\text { Waste Management And } \\
\text { Research }\end{array}$ & 28 & 322 & 12 & 0.6 \\
\hline$J C P$ & $\begin{array}{l}\text { Journal of Cleaner } \\
\text { Production }\end{array}$ & 27 & 405 & 15 & 1.7 \\
\hline CBM & $\begin{array}{l}\text { Construction and } \\
\text { Building Materials }\end{array}$ & 8 & 189 & 24 & 1.5 \\
\hline Sust & $\begin{array}{l}\text { Sustainability } \\
\text { (Switzerland) }\end{array}$ & 7 & 31 & 4 & 0.8 \\
\hline OCBTJ & $\begin{array}{l}\text { Open Construction and } \\
\text { Building Technology } \\
\text { Journal }\end{array}$ & 6 & 34 & 6 & 0.5 \\
\hline$R S E R$ & $\begin{array}{l}\text { Renewable and } \\
\text { Sustainable Energy } \\
\text { Reviews }\end{array}$ & 6 & 130 & 22 & 1.4 \\
\hline WBV & $\begin{array}{l}\text { Waste and Biomass } \\
\text { Valorization }\end{array}$ & 5 & 48 & 10 & 0.4 \\
\hline$I J L C A$ & $\begin{array}{l}\text { International Journal of } \\
\text { Life Cycle Assessment }\end{array}$ & 3 & 57 & 19 & 1.8 \\
\hline$J H M$ & $\begin{array}{l}\text { Journal of Hazardous } \\
\text { Materials }\end{array}$ & 3 & 46 & 15 & 1.6 \\
\hline$J I E$ & $\begin{array}{l}\text { Journal of Industrial } \\
\text { Ecology }\end{array}$ & 35 & 12 & 1.6 \\
\hline
\end{tabular}

${ }^{1}$ The Ave. Norm. Citation represents the normalized number of citations of a journal source, article, scholar, a country, or an organization. It is calculated from dividing the total number of citations by the average number of citations published per year. The normalization corrects the misinterpretation that older documents gain more time 
to receive citations than more recent publications (van Eck and Waltman, 2017). The Ave. Norm. Citation is also applied in following tables which measure the influence of keywords, scholars, articles, or countries that are active in C\&D waste management research.

In Fig. 3, the font and node sizes visually represent the number of publications from the given journals, with larger font and node sizes indicating larger numbers of publications. The clusters represented by different colors and connection lines indicate the closeness among journals in terms of mutual citations. Citation is one of the major measurements of influence of scholarly works, and the use of direct citation is a common measure to identify influential studies in a domain (Van Eck and Waltman, 2014). It is seen that the following journals have been contributing significantly to the research community in $\mathrm{C} \& \mathrm{D}$ waste management: Waste Management (WM), Resources, Conservation, and Recycling, Journal of Cleaner Production (RCR), and Waste Management and Research (WMR). More quantitative measurements of journals’ influences are summarized in Table 1.

Four major measurements listed in Table 1, including number of publications, total citations received, average citation per publication, and average normalized citation quantify the influence of journals in the domain of C\&D waste management. While the former two measurements are generally highly correlated to each other, the average citation related measurements, however, could be independent of the former two measurements; i.e., a journal that is productive in terms of number of publications or total citations may not have the highest citation or normalized average citation per article. Fig. 3 and Table 1 show the consistent results regarding the most productive journals, which are $W M$ and $R C R$. They are also the journals receiving the highest average citations, indicating their highest influence in terms of both production and research significance. In terms of the average normalized citation, WM and $R C R$ were among the journals with the highest average yearly influence, together with a few other journals including International Journal of Life Cycle Assessment, and Journal of Cleaner Production. However, WMR, although with higher average citation, did not have high 
average yearly citation. Table 1 further displays some journals that are not ranked top in terms of production, but having significant contributions according to the average citations. These include Construction and Building Materials, Renewable and Sustainable Energy Reviews, Journal of Hazardous Materials, and Journal of Industrial Ecology.

\subsection{Co-occurrence of keywords}

Keywords represent the main contents of existing studies and depict the topics that have been focused on within a given domain (Su and Lee, 2010). A network of keywords displays the knowledge among their relationships and intellectual organization of research themes (Van Eck and Waltman, 2014). Following the recommendations of Oraee et al. (2017) and Hosseini et al. (2018), the authors of this paper used “Author Keywords" and "Fractional Counting” in VOSViewer analysis. The minimum occurrence of a keyword was set at 3 . Initially 77 out of 992 keywords met the threshold, from which some general items were removed, e.g., “construction and demolition waste," “construction waste," and "construction.” Some other keywords with the same semantic meanings, such as "building information modeling” versus “BIM”, and "recycled aggregate” versus "recycled aggregates,” were combined in the secondround keyword analysis. Finally, a total of 43 keywords were selected, as shown in Fig. 4 and Table 2. 


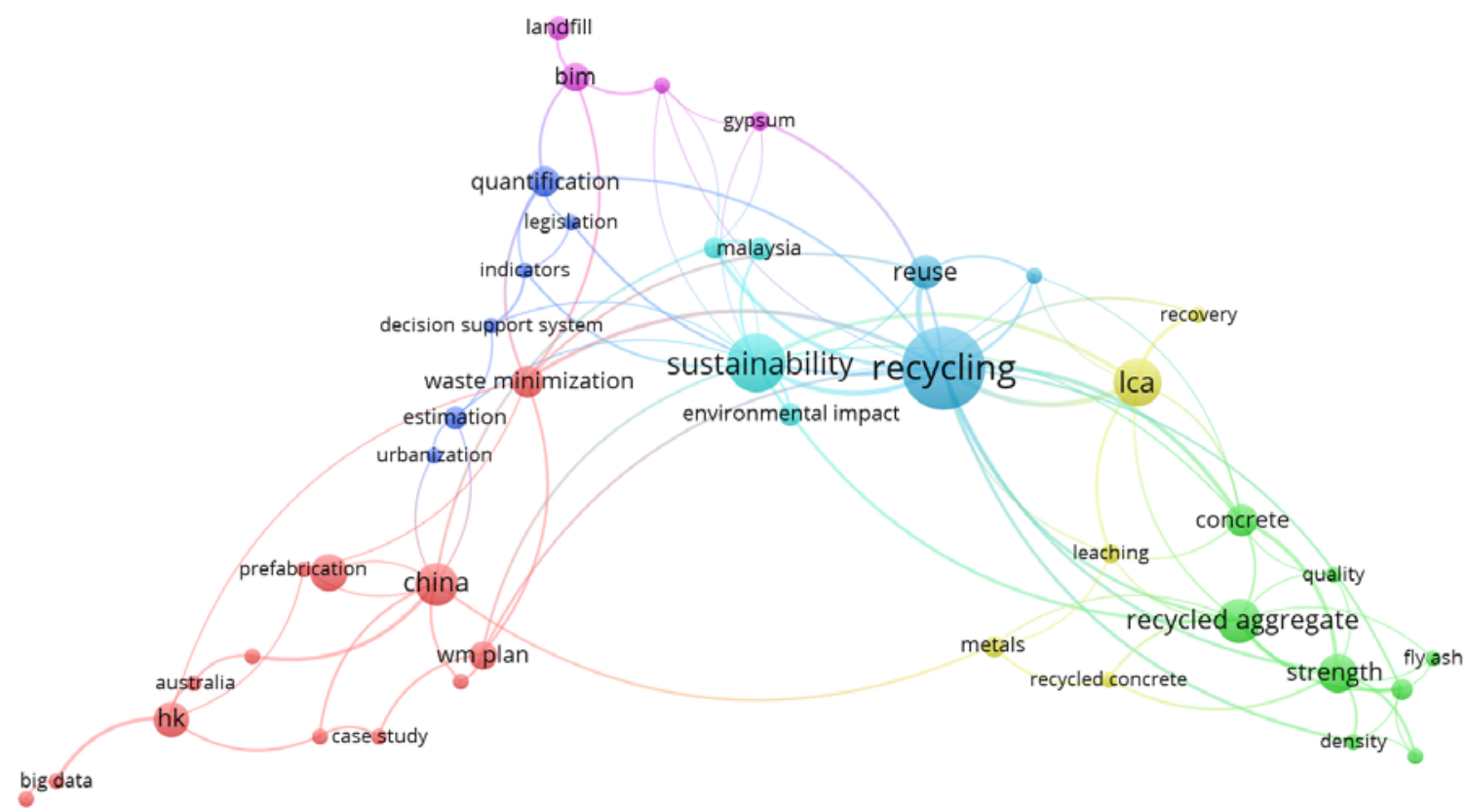

Note: LCA, HK, and WM denote life cycle assessment, Hong Kong, and waste management, respectively.

Fig.4. Co-occurrence of keywords in C\&D waste management research

The node sizes, distances among nodes, and connection lines among keywords visualized in Fig.4 display these most frequently studied terms, including but not limited to sustainability, recycling, reuse, China, BIM, and prefabrication. The colors of nodes divide these keywords into different clusters. It can be found from Fig.4 that concrete, recycled aggregate, and strength are strongly related to each other within the same cluster. Keywords from different clusters may also be strongly linked, such as BIM and quantification. Generally, the mainstream research keywords within $C \& D$ waste management can be categorized in terms of waste treatment methods, sustainability impact, waste materials and technical studies, waste management approach, quantification of waste generation, newly emerging technologies (e.g., BIM), as well as research methods and countries active in C\&D waste management:

- Waste treatment methods: The waste treatment method hierarchy from disposal, recycling, reuse, and reduction has been shown in multiple earlier studies (Shen et al., 2004; Yuan and Shen, 2011). Recycling remains the major method for C\&D waste diversion in the recent decade; 
- Sustainability impact: The environmental impact has been widely studied within the research theme of sustainability. Existing studies show that C\&D waste treatment methods have affected sustainability in multiple dimensions, including energy consumption (Poulikakos et al., 2017), carbon footprint (Coelho and Brito, 2013; Kucukvar et al., 2014), and other environmental issues (Zhang et al., 2012);

- Waste materials and technical studies: One of the main research areas in C\&D waste management is focused on the type of waste materials and technical studies of waste material properties. The widely studied types of C\&D waste materials include concrete (Matias et al., 2013), brick (Jelić et al., 2018), asphalt (Arm et al., 2017), and ceramics (Cabrera-Covarrubias et al., 2017). Recycled aggregates (Al-Bayati et al., 2018; Sim and Park, 2011) are usually the initial forms after the treatment of waste materials generated from C\&D activities. Reuse and recycling of waste concrete or bricks (Zega and Di Maio, 2011) has been an ongoing research area. The properties of recycled products are a key concern because the lower quality may restrict their applications in engineering practice (Jin and Chen, 2015; Jin et al., 2017);

- Waste management approach: The waste management approach has been widely incorporated with life cycle assessment (LCA). Specifically, LCA was applied in the levels of project or building (Zambrana-Vasquez et al., 2016), material or building elements such as concrete (Mah et al., 2017; Sou et al., 2016), and the C\&D waste management system (Bovea and Powell, 2016). Recovery, as one type of waste treatment method, was strongly linked to the LCA approach in multiple studies such as Dahlbo et al. (2015), Puskás et al. (2014), and Arm et al. (2017);

- Quantification of waste generation: Quantification and estimation (Ferreira-Sánchez and Marrero, 2017; Llatas and Osmani, 2016; Mah et al., 2016) of waste generation or waste generation rate (WGR) has been one of the popular research topics. For example, Mah et 
al. (2017) proposed a theoretical method to guide the WGR estimate. Design, modeling, validation, and implementation of WGR or measurement of waste generation are the main focuses within these studies (Ding and Xiao, 2014; Parisi Kern et al., 2015);

- Newly emerging technologies: The applicability of emerging digital technologies (e.g., BIM and big data) in C\&D waste management has been studied. For example, Kim et al. (2017) applied BIM in the building design stage to estimate the amount of demolition waste. This technology is believed to have large potential for more efficient waste management throughout the project life cycle based on its functions in design review, 3D coordination, quantity take-off, and phase planning (Won and Cheng, 2017). Big data analytics was applied by Chen and Lu (2017) to study the inter-relationships among waste generation and multiple factors such as demolition cost, demolition duration, and public-private nature of a building project;

- Research methods and countries active in $C \& D$ waste management: As predicted by Yuan and Shen (2011), more C\&D waste management research would be conducted in developing economies. According to Fig. 4., it can be seen that China has become active in $\mathrm{C} \& \mathrm{D}$ waste management during the past ten years, and the effects of prefabrication (an emerging construction technique) on waste reduction was studied in China (Li et al., 2014).

More quantitative measurements of keywords are summarized in Table 2.

Table 2. Summaries of main keywords in C\&D waste management research

\begin{tabular}{|l|c|c|c|c|}
\hline $\begin{array}{c}\text { Keywords in C\&D waste } \\
\text { management research }\end{array}$ & Occurrence & $\begin{array}{c}\text { Average Year } \\
\text { Published }\end{array}$ & $\begin{array}{c}\text { Average } \\
\text { Citations }\end{array}$ & $\begin{array}{c}\text { Ave. } \\
\text { Norm. } \\
\text { Citation }\end{array}$ \\
\hline Recycling & 51 & 2014 & 13 & 0.8 \\
\hline Sustainability & 28 & 2014 & 12 & 0.9 \\
\hline LCA & 20 & 2015 & 12 & 1.6 \\
\hline Recycled Aggregate & 17 & 2014 & 14 & 1.7 \\
\hline China & 16 & 2014 & 26 & 1.7 \\
\hline Strength & 14 & 2013 & 27 & 1.1 \\
\hline System Dynamics & 13 & 2014 & 23 & 1.6 \\
\hline HK & 12 & 2013 & 14 & 1.4 \\
\hline Reuse & 11 & 2014 & 16 & 1.0 \\
\hline Concrete & 10 & 2013 & 24 & 0.9 \\
\hline
\end{tabular}




\begin{tabular}{|l|c|c|c|c|}
\hline Waste Minimization & 10 & 2014 & 7 & 0.5 \\
\hline Quantification & 9 & 2014 & 16 & 1.3 \\
\hline BIM & 8 & 2016 & 14 & 1.5 \\
\hline WM Plan & 8 & 2012 & 5 & 0.3 \\
\hline Environmental Impact & 6 & 2014 & 12 & 0.7 \\
\hline Estimation & 6 & 2014 & 9 & 0.8 \\
\hline Landfill & 6 & 2016 & 9 & 1.7 \\
\hline Malaysia & 6 & 2016 & 2 & 0.7 \\
\hline Circular Economy & 5 & 2017 & 1 & 1.5 \\
\hline Metals & 5 & 2015 & 8 & 1.0 \\
\hline Recycled Concrete Aggregate & 5 & 2014 & 15 & 1.2 \\
\hline Gypsum & 4 & 2013 & 7 & 0.8 \\
\hline Leaching & 4 & 2014 & 19 & 1.8 \\
\hline Australia & 3 & 2013 & 38 & 2.0 \\
\hline Big Data & 3 & 2016 & 14 & 3.6 \\
\hline Case Study & 3 & 2013 & 11 & 0.6 \\
\hline Decision Support System & 3 & 2013 & 16 & 0.8 \\
\hline Density & 3 & 2013 & 17 & 1.0 \\
\hline Factor Analysis & 3 & 2013 & 19 & 1.3 \\
\hline Fly Ash & 3 & 2013 & 17 & 0.7 \\
\hline Indicators & 3 & 2014 & 14 & 0.8 \\
\hline Legislation & 3 & 2013 & 18 & 1.0 \\
\hline Prefabrication & 3 & 2013 & 14 & 1.1 \\
\hline Quality & 3 & 2012 & 4 & 0.1 \\
\hline Recovery & 3 & 2014 & 11 & 1.3 \\
\hline Recycled Concrete & 2014 & 26 & 1.4 \\
\hline Urbanization & 3 & 2017 & 3 & 1.8 \\
\hline Waste Prevention & 3 & 2016 & 2 & 0.6 \\
\hline Waste Sorting & 3 & 2012 & 34 & 1.8 \\
\hline Water Absorption & 3 & 616 & 0.4 \\
\hline Waste Generation Rate & 3 & 6 & 1.3 \\
\hline keywords Table & 3 & 2 & \\
\hline
\end{tabular}

Note: keywords in Table 2 are listed according to their occurrences, from highest to lowest.

Table 2 summarizes the quantitative measurements of the identified keywords. According to their average citations, the following keywords including waste sorting, strength, recycled concrete, China, and Australia have received more attention in the research community. In those related articles, strength refers to the quality or properties of recycled products (e.g., concrete made from recycled aggregates). It can be seen that balancing quality and sustainability has become a wide concern in research. The average year of publication indicates the recentness of a given keyword in the domain of C\&D waste management. For example, studies focusing on the waste management plan and quality of recycled products were largely published around 2012, showing that these two topics have been studied comparatively early. In contrast, papers related to BIM, Circular Economy, Big Data, urbanization, waste prevention, and WGR were published around 2016 or 2017, indicating that these emerging themes caught 
researchers' attention in more recent years and may represent future research directions. The average normalized citation values also indicate that these keywords have aroused high attention in the research community of C\&D waste management, especially Big Data, which had significantly higher average normalized citation than any other keywords in Table 2.

\subsection{Co-authorship analysis}

It is commonplace to see collaborations among scholars in academic research. Awareness of the existing collaborations in a research domain can prevent researchers from isolation and improve productivity (Hosseini et al., 2018). For this co-authorship analysis in C\&D waste management research, the minimum number of articles published and the minimum citations of an author set in VOSviewer are 5 and 30 respectively. Totally 24 out of 919 authors from the literature sample met the selection criteria. These most influential authors are presented in Fig. 5 and Table 3. It can be seen in Fig. 5 that these authors are divided into three categories, representing the research network of three groups of scholars in C\&D waste management, for example, the research group of Yuan H., Lu W., Chen X., Shen L., and Zhang X.

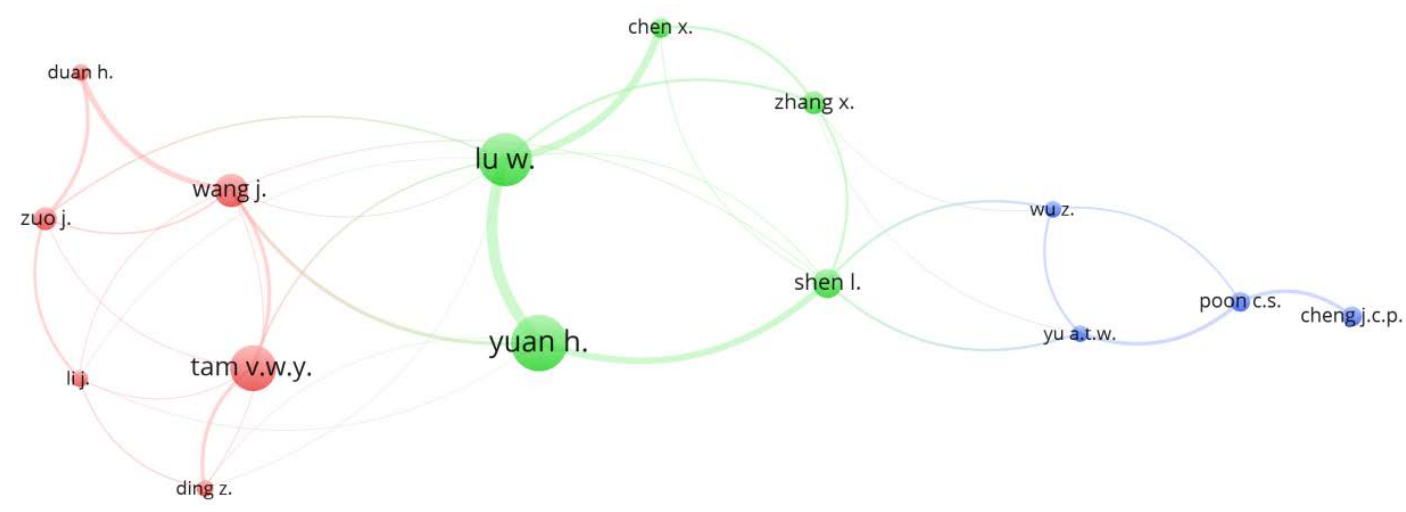

Fig.5. Co-authorship analysis in C\&D waste management research

Table 3. Quantitative measurements of scholars in C\&D waste management research

\begin{tabular}{|c|l|c|c|c|c|c|}
\hline Scholar & \multicolumn{1}{|c|}{ Affiliation } & $\begin{array}{c}\text { Number } \\
\text { of } \\
\text { articles }\end{array}$ & $\begin{array}{c}\text { Total } \\
\text { citations }\end{array}$ & $\begin{array}{c}\text { Average } \\
\text { publication } \\
\text { year }\end{array}$ & $\begin{array}{c}\text { Average } \\
\text { citations }\end{array}$ & $\begin{array}{c}\text { Ave. } \\
\text { Norm. } \\
\text { Citations }\end{array}$ \\
\hline Yuan H. & Southwest Jiaotong University & 17 & 741 & 2012 & 44 & 2.0 \\
\hline Lu W. & The University of Hong Kong & 16 & 454 & 2014 & 28 & 2.0 \\
\hline
\end{tabular}




\begin{tabular}{|c|l|c|c|c|c|c|}
\hline Shen L. & Chongqing University & 9 & 310 & 2013 & 34 & 2.4 \\
\hline Tam V.W.Y. & Western Sydney University & 14 & 281 & 2013 & 20 & 1.3 \\
\hline Wang J. & Shenzhen University & 10 & 249 & 2014 & 25 & 2.1 \\
\hline Poon C.S. & Hong Kong Polytechnic University & 6 & 205 & 2014 & 34 & 2.2 \\
\hline Cheng J.C.P. & The Hong Kong University of Science & 6 & 119 & 2016 & 20 & 2.3 \\
and Technology & 6 & 5 & 117 & 2014 & 23 & 1.4 \\
\hline Li J. & Hong Kong Polytechnic University & 5 & 109 & 2015 & 22 & 1.5 \\
\hline Ding Z. & Shen Zhen University & 5 & 101 & 2015 & 20 & 2.2 \\
\hline Yu A.T.W. & Hong Kong Polytechnic University & 7 & 66 & 2015 & 9 & 1.2 \\
\hline Zhang X. & City University of Hong Kong & 7 & 65 & 2016 & 9 & 1.4 \\
\hline Zuo J. & University of Adelaide & 5 & 62 & 2016 & 12 & 2.1 \\
\hline Wu Z. & Shenzhen University & 6 & 48 & 2016 & 8 & 2.3 \\
\hline Chen X. & The University of Hong Kong & 5 & 31 & 2016 & 6 & 1.3 \\
\hline Duan H. & Shenzhen University & & &
\end{tabular}

Note: Scholars in Table 3 are listed according to the total citations.

Table 3 presents the five major quantitative measurements of these scholars, namely total link strength, number of articles published, total citations in Scopus, the average year of publication, and average citations per article. The former three measurements display the production of research outputs and the influence of the given author to the research community. According to Table 3, Yuan $\mathrm{H}$. is the most productive author in the domain of C\&D waste management, with significantly more total citations than other authors. Yuan H. also ranks the first in total number of articles and average citations, indicating that Yuan H. is both productive and influential in this domain. Other scholars with significant contributions to the research community include Shen L., Poon C.S., and Lu W. These scholars have also been collaborative as visualized in Fig. 5. The average publication year of scholars provides the information of emerging scholars including Zuo J., Wu Z., Chen X., and Duan H, whose publications are generally around 2016. The normalized citation analysis indicates the average yearly influence of scholars. Shen L., Cheng, J.C.P., and Chen, X., although not with the highest number of publication nor the average citation, have contributed significantly to the research of C\&D waste management considering their yearly influence. Some other productive scholars, including Xiao J., and Brito, J. were not identified through text mining in Table 3, due to the 
fact that this study focused on the management level of C\&D waste, but not on technical properties of recycled products (e.g., recycled aggregate concrete).

\subsection{Citation of articles}

The most influential journal publications in the last ten years were also investigated in VOSViewer, with the minimum citations set at 50. This resulted in a total of 27 out of 370 articles being selected. Among them, the most influential articles measured by citations are visualized in Fig. 6. Consistent to the findings in Fig. 5 and Table 3, Fig. 6 further illustrates that Yuan H. has been leading a series of studies that contributed significantly to the research domain of C\&D waste management.

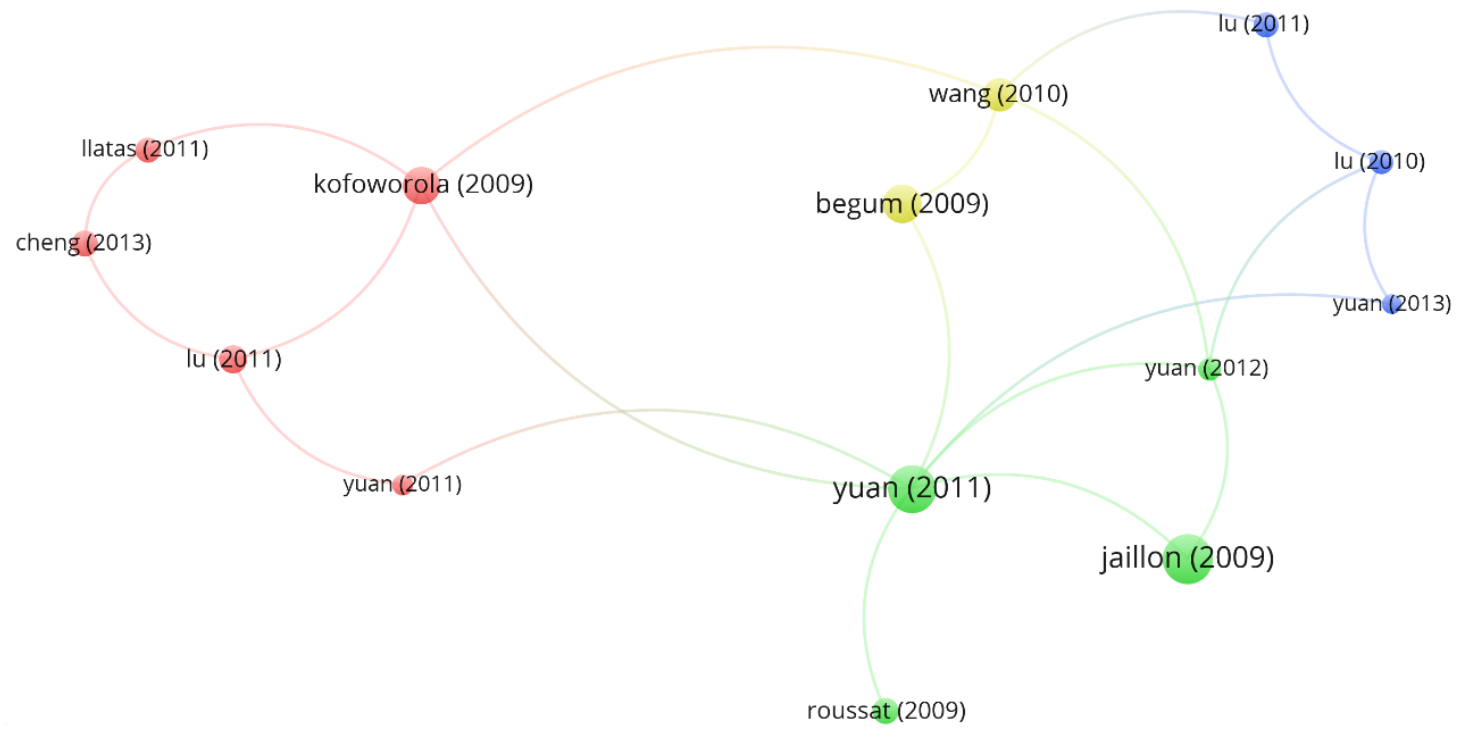

Note: only the first author of each article is displayed in VOSViewer, more details of each article can be found in Table 4. Yuan (2011a) is the same as Yuan and Shen (2011); Yuan (2011b) refers to Yuan et al. (2011).

Fig.6. Science mapping of most influential publications in C\&D waste management research

More details of these articles, including their full tile, number of links and total citations are summarized in Table 4.

Table 4. List of publications with the highest impact in C\&D waste management

\begin{tabular}{|c|c|c|c|}
\hline & Title & $\begin{array}{c}\text { Ave. } \\
\text { cumber of } \\
\text { citations }\end{array}$ & $\begin{array}{c}\text { Norm. } \\
\text { Citations }\end{array}$ \\
\hline
\end{tabular}




\begin{tabular}{|c|c|c|c|}
\hline $\begin{array}{l}\text { Jaillon et al. } \\
(2009)\end{array}$ & $\begin{array}{l}\text { Quantifying the waste reduction potential of using } \\
\text { prefabrication in building construction in Hong Kong }\end{array}$ & 124 & 3.3 \\
\hline $\begin{array}{l}\text { Yuan and Shen } \\
\text { (2011) }\end{array}$ & $\begin{array}{l}\text { Trend of the research on construction and demolition waste } \\
\text { management }\end{array}$ & 120 & 4.6 \\
\hline $\begin{array}{l}\text { Begum et al., } \\
\text { (2009) }\end{array}$ & $\begin{array}{l}\text { Attitude and behavioral factors in waste management in the } \\
\text { construction industry of Malaysia }\end{array}$ & 97 & 2.6 \\
\hline $\begin{array}{l}\text { Kofoworola and } \\
\text { Gheewala } \\
(2009)\end{array}$ & $\begin{array}{l}\text { Estimation of construction waste generation and } \\
\text { management in Thailand }\end{array}$ & 94 & 2.5 \\
\hline $\begin{array}{l}\text { Wang et al., } \\
(2010)\end{array}$ & $\begin{array}{l}\text { Critical success factors for on-site sorting of construction } \\
\text { waste: A china study }\end{array}$ & 84 & 2.9 \\
\hline $\begin{array}{l}\text { Lu and Yuan } \\
(2011)\end{array}$ & $\begin{array}{l}\text { A framework for understanding waste management studies } \\
\text { in construction }\end{array}$ & 72 & 2.7 \\
\hline $\begin{array}{l}\text { Roussat et al. } \\
\text { (2009) }\end{array}$ & $\begin{array}{l}\text { Choosing a sustainable demolition waste management } \\
\text { strategy using multicriteria decision analysis }\end{array}$ & 66 & 1.7 \\
\hline $\begin{array}{l}\text { Cheng and Ma } \\
\text { (2013) }\end{array}$ & $\begin{array}{l}\text { A BIM-based system for demolition and renovation waste } \\
\text { estimation and planning }\end{array}$ & 65 & 3.2 \\
\hline Llatas (2011) & $\begin{array}{l}\text { A model for quantifying construction waste in projects } \\
\text { according to the European waste list }\end{array}$ & 63 & 2.4 \\
\hline Lu et al. (2011) & $\begin{array}{l}\text { An empirical investigation of construction and demolition } \\
\text { waste generation rates in Shenzhen city, South China }\end{array}$ & 62 & 2.4 \\
\hline $\begin{array}{l}\text { Lu and Yuan } \\
(2010)\end{array}$ & $\begin{array}{l}\text { Exploring critical success factors for waste management in } \\
\text { construction projects of China }\end{array}$ & 60 & 2.1 \\
\hline $\begin{array}{l}\text { Yuan et al. } \\
(2012)\end{array}$ & $\begin{array}{l}\text { A dynamic model for assessing the effects of management } \\
\text { strategies on the reduction of construction and demolition } \\
\text { waste }\end{array}$ & 57 & 3.4 \\
\hline $\begin{array}{l}\text { Yuan et al. } \\
\text { (2011b) }\end{array}$ & $\begin{array}{l}\text { A model for cost-benefit analysis of construction and } \\
\text { demolition waste management throughout the waste chain }\end{array}$ & 52 & 2.0 \\
\hline Yuan (2013) & $\begin{array}{l}\text { A SWOT analysis of successful construction waste } \\
\text { management }\end{array}$ & 51 & 2.5 \\
\hline
\end{tabular}

Note: the articles in Table 4 are listed according to the number of citations.

The article that has received the highest number of citations in the recent decade is Jaillon et al. (2009), one of the earliest studies to link prefabricated construction to waste reduction. Prefabricated or off-site construction is a new construction technique that moves the building construction process away from the site into a controlled factory environment (Jiang et al., 2018). Although prefabricated construction is still at its early stage of implementation in some developing countries such as China (Hong et al., 2018), it is gaining increasing application in the construction market. Two of main benefits of using prefabricated construction are waste reduction and being lean (Hong et al., 2016). The review-based research of Yuan and Shen (2011) has received the second-highest citation rate and in the recent decade. Some of the trends they proposed, including evaluation of the effectiveness of waste recycling from a sustainable perspective and improvement of practitioners' attitudes towards $C \& D$ waste recycling and reuse, are still ongoing research topics. The third-highest-cited article by Begum et al. (2009) 
focused on the human attitudes and behavior issues. The main themes in other highly cited articles include: 1) estimate of waste generation (Kofoworola and Gheewala, 2009; Lu et al., 2011); 2) strategies and framework in waste management (Lu and Yuan, 2011; Roussat et al., 2009); 3) a modeling approach to evaluate strategies or quantify waste generation (Llatas, 2011; Yuan et al., 2011b; Yuan et al., 2012); 4) critical success factors and SWOT analysis (i.e., strength, weakness, opportunity, and threat) in C\&D waste management ( $\mathrm{Lu}$ and Yuan, 2010; Yuan, 2013); and 5) application of the newly emerging digital technologies (i.e., BIM) (Cheng and Ma, 2013). In terms of the average normalized citation, Yuan and Shen (2011) who provided review of C\&D waste management studies, Yuan et al (2012) in developing assessment models, and Cheng and Ma (2013) introducing BIM have received the highest yearly-based attention in the academic community.

\subsection{Countries active in $C \& D$ waste management research}

Keyword analysis in Fig. 4 and Table 2 indicates several countries that are active in the research of C\&D waste management. These include both developed and developing economies such as China and Australia. VOSViewer was used in this study to further identify and evaluate these countries' contributions to the global research community, with the minimum numbers of documents and citations of a country set at 3 and 30, respectively. This resulted in totally 25 out of 60 countries short-listed. Fig. 7 and Table 5 present the findings of countries that have been active in C\&D waste management research in the recent decade. 


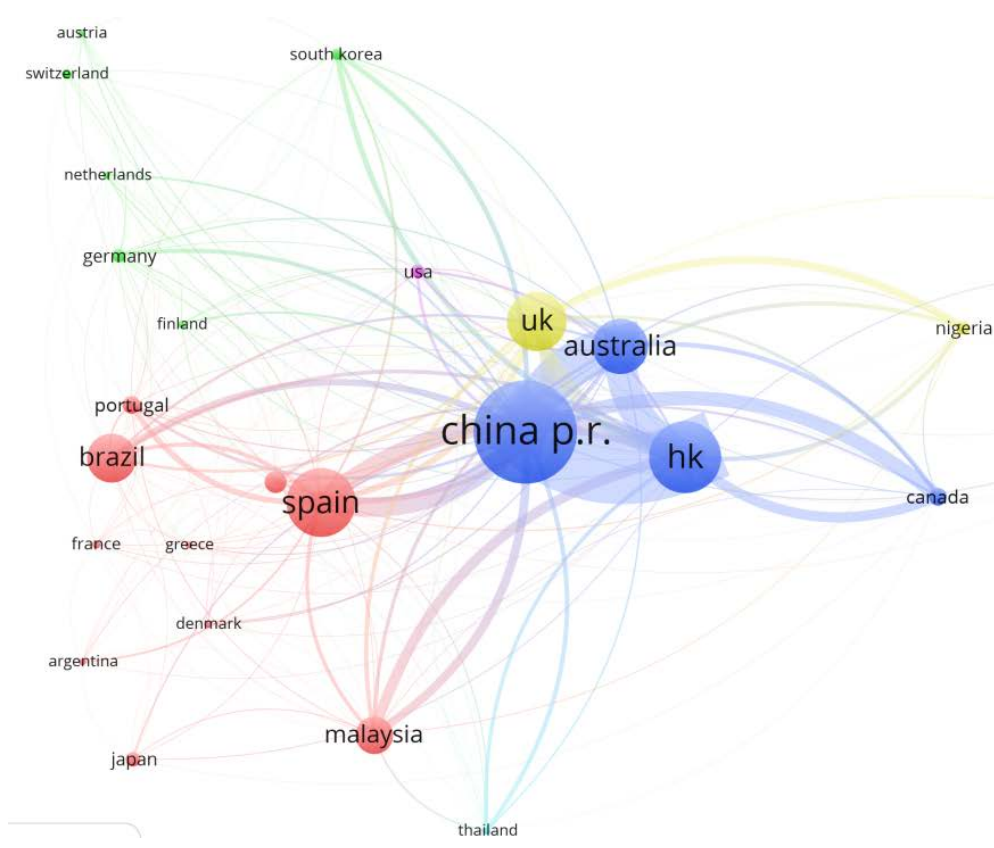

Fig.7. Mapping of countries active in C\&D waste management research

The connection lines in Fig. 7 show the mutual citations of studies among different countries, which can be further measured by the total link strength in Table 5. It can be seen in Fig. 7 that the following countries or regions have been contributing to the research community according to their node sizes and connection lines with other countries: mainland China, Hong Kong, U.K., Spain, Brazil, U.S., and Malaysia. Especially, as predicted by Yuan et al. (2011a), more developing countries have become active in C\&D waste diversion. Insufficient landfill spacing, lack of legislation, and various other concerns have been identified in countries, such as Vietnam (Ling and Nguyen, 2013), Malaysia (Lachimpadi et al., 2012), Nigeria (Yusuf et al., 2016), and Brazil (Ferreira-Sánchez and Marrero, 2017). More quantitative measurements including number of articles published, total and average citations, and the average year of publication are provided in Table 5.

Table 5. Countries active in C\&D waste management research

\begin{tabular}{|l|c|c|c|c|c|}
\hline \multicolumn{1}{|c|}{ Country } & $\begin{array}{c}\text { Number of } \\
\text { publications }\end{array}$ & $\begin{array}{c}\text { Number of } \\
\text { citations }\end{array}$ & $\begin{array}{c}\text { Average } \\
\text { publication year }\end{array}$ & $\begin{array}{c}\text { Average } \\
\text { citation }\end{array}$ & $\begin{array}{c}\text { Ave. } \\
\text { Norm. } \\
\text { Citation }\end{array}$ \\
\hline China. P.R. & 69 & 1178 & 2014 & 17 & 1.5 \\
\hline Hong Kong & 48 & 1225 & 2013 & 26 & 1.8 \\
\hline Spain & 46 & 798 & 2014 & 17 & 1.2 \\
\hline
\end{tabular}




\begin{tabular}{|l|c|c|c|c|c|}
\hline United Kingdom & 40 & 315 & 2015 & 8 & 1.1 \\
\hline Australia & 37 & 406 & 2014 & 11 & 1.1 \\
\hline Brazil & 33 & 187 & 2014 & 6 & 0.4 \\
\hline Malaysia & 25 & 180 & 2015 & 7 & 0.6 \\
\hline Italy & 15 & 192 & 2015 & 13 & 1.2 \\
\hline Canada & 12 & 329 & 2012 & 27 & 1.1 \\
\hline Portugal & 12 & 245 & 2014 & 20 & 1.6 \\
\hline Japan & 10 & 53 & 2014 & 5 & 0.7 \\
\hline Germany & 9 & 223 & 2013 & 25 & 1.6 \\
\hline Nigeria & 9 & 74 & 2015 & 8 & 1.2 \\
\hline United States & 9 & 120 & 2012 & 13 & 1.0 \\
\hline South Korea & 8 & 87 & 2016 & 11 & 0.9 \\
\hline France & 6 & 83 & 2014 & 14 & 1.3 \\
\hline Austria & 5 & 38 & 2016 & 8 & 1.7 \\
\hline Denmark & 5 & 58 & 2016 & 12 & 1.4 \\
\hline Greece & 5 & 96 & 2012 & 19 & 1.6 \\
\hline Netherlands & 5 & 132 & 2012 & 26 & 1.0 \\
\hline Argentina & 4 & 98 & 2012 & 25 & 1.1 \\
\hline Finland & 4 & 50 & 2015 & 13 & 1.5 \\
\hline Pakistan & 4 & 30 & 2015 & 8 & 0.9 \\
\hline Switzerland & 4 & 64 & 2013 & 16 & 1.7 \\
\hline Thailand & 4 & 99 & 2014 & 25 & 0.9 \\
\hline
\end{tabular}

Scholars from mainland China and Hong Kong rank the top in terms of number of publications and and total citations, followed by Spain, U.K., and Australia. Mainland China is facing a shortage of landfilling space in handling the tremendous amount of C\&D wastes (Duan and Li, 2016). In Hong Kong, due to its relatively limited land resources and high density of population, C\&D waste management has become a major environmental issue (Poon et al., 2004). Developed countries, such as Japan, Australia, and U.K, although not having as many publications as mainland China, Hong Kong, and Malaysia do, started their research in C\&D waste diversion in earlier years. Some of them (e.g., Japan) have already developed more advanced technologies and legislations to encourage or mandate sustainable $C \& D$ waste reuse (Jin and Chen, 2015; Jin and Chen, 2018). The average normalized citation measurement indicates that developed countries or regions including Hong Kong, Austria, Switzerland, Portugal, and Germany have created higher yearly impact in the research community. A comprehensive analysis of these multiple quantitative measurements listed in Table 5 indicate 
potential correlation between a country's scholarly publication and its influencing factors that affect C\&D waste diversion. These influencing factors include but are not limited to lack of landfilling space (Yuan et al., 2011b), insufficient legislation or policy (Ajayi and Oyedele, 2017), immature recycling market (Huang et al., 2018), and high population density (Jin et al., 2017). These factors could drive the scholarly research in some developing countries such as China and Brazil in terms of number of publications. However, there is limited evidence to show causal relationships between these influencing factors and and the scholarly outputs for a certain country or region. Further research work is needed to analyze the relationship between a country’s influencing factors to C\&D waste diversion and its scholarly outputs.

\section{Qualitative Discussions}

Following the scientometric analysis, this study carried on an in-depth discussion to summarize the contemporary mainstream research topics, identify research limitations, and propose the framework for future research directions. The findings are reported below.

\subsection{Research topics within C\&D waste management}

C\&D waste management is a multi-disciplinary domain, covering various subjects, including construction and project management, civil engineering, environmental science, and

others (e.g., social science). Depending on the research objectives, different research methods could be adopted, for example, review of existing guidelines or literature (Rose and Stegemann, 2018; Yuan, 2017), interview (Akinade et al., 2018), questionnaire survey ( $\mathrm{Li}$ et al., 2018a), case study (Xue et al., 2017), computer simulation (Zanna et al., 2017), method development in estimating wastes (Zheng et al., 2017), modeling (Rahimi and Ghezavati, 2018), and site investigation (Kleemann et al., 2016). This study divides the mainstream research topics in C\&D waste management into the following major categories.

\subsubsection{Estimate and quantification of waste generation}


Estimate and quantification of C\&D waste generation is needed across project delivery stages, including the design, construction, and operation. Counting the amounts of C\&D waste generation is still in need of benchmarking criteria or established framework and methods. Kleemann et al. (2017) provided a statistical approach to estimate waste generated from building demolition in the case of lack of data. More data analytics approaches, as tried by Cheng et al. (2018), could be applied in C\&D waste generation. Sáez et al. (2015) extended the estimation method from solely total project floor area based to also incorporating the number of dwellings. Compared to the more traditional approach, this method reduces the estimate error. It was expected to serve as a guide for stakeholders to estimate the amount of construction wastes. Also, multiple statistical, data mining, and modeling approaches have been applied to estimate the construction waste. For example, Parisi Kern et al. (2015) applied the regression analysis by adopting the design and product system as independent variables. The best regression model identified in their work achieved nearly 70\% accuracy. Ding and Xiao (2014) considered more factors that affect waste generation, such as building design and structure codes. Furthermore, more advanced information technology or automation have been tried in assisting the waste estimate. For example, the web-based construction waste estimation system developed by Li and Zhang (2013) incorporates work breakdown structure, material quantity takeoff, material classification, material conversion ratios, material wastage levels, and the mass balance principle. It was indicated by these studies that the quality, size, and reliability of database is critical to develop, validate, and apply the waste estimation method. Based on existing studies (María et al., 2016; Masudi et al., 2012; Mercader-Moyano and Ramírez-DeArellano-Agudo, 2013), ways to enhance the database of waste generation include but are not limited to: incorporating the geographic location and waste material factors in the waste estimation model; comparing the primary and secondary data in waste generation; as well as classification of building types (e.g., new or renovation). Last but not least, BIM, as an 
emerging digital technology, has been examined for its potential use in waste management from design to demolition, including the estimate of waste generation in the early design stage (Kim et al., 2017).

\subsubsection{C\&D waste diversion research in developing economies}

In the recent decade, more studies in $C \& D$ waste diversion have been carried out in developing economies with an emphasis on the external and internal factors that may affect the C\&D waste diversion practice. Governmental support was considered one of the main external factors, together with the local market and availability of urban space for landfilling (Nikmehr et al., 2017; Yuan, 2013). The key internal factors related to sustainable use of waste or waste efficiency include material procurement in the project delivery process (Ajayi et al., 2017a), waste management system (Lu and Yuan, 2010), human factors (Bakshan et al., 2017; Lu and Yuan, 2010), research and development (Yuan, 2013), design management (Ajayi et al., 2017b), waste sorting strategies (Wang et al., 2010), and low-waste technologies (Bilal et al., 2015). Researchers have identified some key barriers to promoting C\&D waste recycling, reuse, and reduction, such as quality of recycled products (Revathi et al., 2013), lack of awareness or culture in waste minimization (Ling and Nguyen, 2013), immature recycling market and regulation (Yuan et al., 2011a), and extra costs for recycling and reuse (da Rocha and Sattler, 2009).

\subsubsection{Design and planning for waste diversion}

Decision making in project design and planning stages has been identified with key impacts on waste minimization and prevention (de Magalhães et al., 2017; Esa et al., 2017b; Ghose et al., 2017). Existing studies have focused on incorporating waste management into design, planning, or tendering stages. (Oladiran, 2009) found that a waste management plan (WMP) could be effective in minimizing material wastes in construction projects. (Laquatra and Pierce, 2009) described the key elements within a WMP, including waste sorting. In 
addition, proper design and construction management was estimated to reduce around $40 \%$ of waste according to (Ding et al., 2018). Design for construction projects is not limited to conventional site-cast concrete, but also includes the newly emerging prefabricated construction or precast concrete. (Baldwin et al., 2009) emphasized that the adoption of prefabrication required the adaption of design to reduce waste and also contractors' involvement in the design stage. (Akinade et al., 2018) listed the waste-driven design process and solutions as one of the major expectations when applying BIM in C\&D waste management.

\subsection{Current research gaps within $C \& D$ waste management}

\subsubsection{Differences in $C \& D$ waste diversion practice among regions and countries}

Tam (2009) compared the concrete recycling practice between two developed countries (i.e., Japan and Australia). Jin and Chen (2015) continued the comparison among developed countries by adding the U.S. Increasing studies have focused on the movement and practice in developing countries such as Vietnam and Pakistan (Doan and Chinda, 2016; Lockrey et al., 2016). However, there can be pitfalls when developing countries try to learn from the experience or to import the $C \& D$ waste treatment technologies from developed countries. How the management, policy, and technological practice from developed countries could be effectively applied in developing countries remains to be studied. There are cultural, economic, and practical differences between developed economies and their developing counterparts. As analyzed by Jin et al. (2017), developing countries may rely more on the governmental policy to drive the industry practice of C\&D waste diversion. According to Wu et al. (2017), Chinese government played a key role in guiding and promoting contractors’ practice in C\&D waste management. Without incentives from governmental bodies, practitioners in C\&D waste management (e.g., supplier of recycled products) may not be able to survive. In comparison, developed countries such as Japan have developed their own market demand and production of recycled products with relevant industry standards, for example, Japanese Industrial 
Standards (2005) on concrete using recycled aggregate. Currently, there have not been sufficient studies to bridge the gaps between developing and developed countries. The systematic comparison of the social, economic, and management aspects in C\&D waste diversion practice would enhance the research and practice worldwide in finding proper $C \& D$ waste management programs in the context of a certain country or region.

\subsubsection{Performance of $C \& D$ waste management}

Although there have been some commonly adopted management programs or incentive policies aiming to enhance the practice of $C \& D$ waste diversion, the effectiveness of these programs or policies, including the landfilling charging rate studied by Coelho and De Brito (2013) and Yuan and Wang (2014), has not been widely addressed. The effectiveness of waste management has not been well benchmarked. One of the adopted criteria in benchmarking C\&D waste management is WGR. According to Lu et al. (2015), a larger database would be needed to develop the WGR benchmarking. Besides waste generation estimate, other measurements have been considered in evaluating the effectiveness of C\&D waste management practice, including cost-efficiency (Lu et al., 2009) or economic performance (Oliveira Neto et al., 2017), environmental impact (Hao and Larney, 2017), or a more comprehensive measurement covering more than one performance indicator (Zanna et al., 2017). The performance measurement for evaluating C\&D waste management can be more comprehensive, for example, how practitioners' attitudes have been changed by a management program or incentive policy as indicated by Yuan and Shen (2011). Currently there are still needs of developing a more comprehensive performance measurement mechanism for C\&D waste management, or a suitable $C \& D$ waste management guide adapted in a certain organizational or local context.

\subsubsection{Human factors in $C \& D$ waste diversion practice}


Human factors covering perceptions, attitudes, behaviors, and expectations could be studied in their relationship to the $C \& D$ waste management program, either in the organizational or local context. More research is needed on human factors involving multiple stakeholders, such as the perceptions, attitudes, and behaviors of the client, contractors, engineers, and facility managers (Wu et al., 2017). These factors may be further studied to form the concept of $C \& D$ waste diversion climate and culture, like the safety climate (Chen and Jin, 2015) and safety culture (Molenaar et al., 2009) in the construction industry. This proposed waste diversion climate and culture could be developed from waste behavioral culture as indicated by Ajayi et al. (2015) and Bakshan et al. (2017). It may involve sub-climate and subculture, depending on multiple subgroup factors, including but not limited to practitioners’ occupations and experience studied by Jin et al. (2017). Currently there have been limited studies that investigate individual or organizational human factors' effects on C\&D waste practice. The concept of climate and culture in C\&D waste management remains rare, compared to their presence in construction safety management.

\subsubsection{Emerging technologies and concepts}

Newly emerging digital technologies and data analytics, such as BIM and big data, have been researched in how they could be applied in C\&D waste quantification and overall project management for waste control. Big data technologies are inherently suitable for BIM due to their support of storing and processing large datasets (Bilal et al., 2015). However, according to Fig. 4, big data has so far not been closely integrated with BIM to assist C\&D waste management. At present, the applications of these new data or digital technologies in $C \& D$ waste quantification, control, monitoring, and overall management are still in the early stage. There can be a more integrated approach to adopt multiple technologies for enhancing the practice of $C \& D$ waste diversion. 
Circular economy is becoming an emerging concept that aims to replace the current production and consumption model based on continuous growth and increasing resource throughput (Ghisellini et al., 2016). It is seen as a new business model leading to a more sustainable development (Naustdalslid, 2014). Circular economy requires a balanced and simultaneous consideration of economic, environmental, technological and social perspectives of an investigated economy, sector, or individual industrial process as well as the interaction among all these perspectives (Ren et al., 2013). It is more than just the approach of appropriate waste management. It might fail in its application in recycling, reuse, or recovery options (Ghisellini et al., 2016). So far there has been limited established body of knowledge or framework for applying circular economy in the context of C\&D waste management. If not properly addressed, applying circular economy may lead to a more expensive solution compared to the conventional approach, or it may be applied in the inappropriate context (Ghisellini et al., 2016), such as resource recovery in certain developing economies. Adopting circular economy in C\&D management would be a big challenge when the related research is still limited (Huang et al., 2018).

\subsection{Research trends within $C \& D$ waste management}

Based on the discussion of mainstream research topics and gaps, the framework of nearfuture directions in C\&D waste management is proposed and shown in Fig. 8. 


\begin{tabular}{|c|c|c|c|c|}
\hline $\begin{array}{l}\text { 1.Quantification and estimate of } \\
\text { WGR; 2. Design, modeling, } \\
\text { simulation, and validation of } \\
\text { waste generation }\end{array}$ & & $C \& D$ waste generation & & $\begin{array}{l}\text { 1. Benchmarking WGR and environmental } \\
\text { impacts; } 2 \text {. Design and planning in waste } \\
\text { generation }\end{array}$ \\
\hline $\begin{array}{l}\text { 1. Recovery; 2. Recycling; } 3 . \\
\text { Reduce; 4. Waste prevention; } 5 . \\
\text { Reuse }\end{array}$ & & $\begin{array}{c}\text { C\&D waste treatment } \\
\text { method }\end{array}$ & & $\begin{array}{l}\text { 1. Developing the implementation system of } \\
\text { waste treatment hierarchy involving re- } \\
\text { manufacturing; } 2 \text {. LCA in both project and } \\
\text { building element/material levels }\end{array}$ \\
\hline 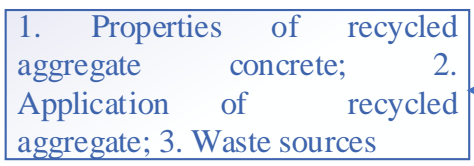 & & $\begin{array}{l}\text { Products containing } \\
\text { recycled contents }\end{array}$ & & $\begin{array}{l}\text { 1. Application of recycled products in } \\
\text { prefabricated components; } 2 \text {. Optimizing } \\
\text { the economic, engineering, and } \\
\text { environmental factors for recycled products }\end{array}$ \\
\hline $\begin{array}{l}\text { 1. Policy, guideline, and } \\
\text { standards; } 2 \text {. Movement of C\&D } \\
\text { waste diversion in developing } \\
\text { economies; } 3 \text {. SWOT analysis }\end{array}$ & & $\begin{array}{c}\text { C\&D waste management } \\
\text { practice }\end{array}$ & & $\begin{array}{l}\text { 1. Developing effective C\&D waste } \\
\text { program in enhancing waste diversion; } 2 . \\
\text { Evaluation of the performance of C\&D } \\
\text { waste diversion }\end{array}$ \\
\hline $\begin{array}{l}\text { 1. Perceptions, attitudes, and } \\
\text { behaviors of practitioners and } \\
\text { stakeholders towards waste } \\
\text { diversion; 2. Waste management } \\
\text { program (e.g., incentives) } \\
\end{array}$ & & $\begin{array}{c}\text { Human Factors in C\&D } \\
\text { waste management }\end{array}$ & & $\begin{array}{l}\text { 1. Studying the C\&D waste diversion } \\
\text { climate and culture; } 2 \text {. studying the impacts } \\
\text { of waste management program on human } \\
\text { perceptions, attitudes, and behaviors }\end{array}$ \\
\hline $\begin{array}{l}\text { 1. BIM } \\
\text { 2. Big data or data analytics } \\
\text { 3. Circular Economy }\end{array}$ & & $\begin{array}{l}\text { Emerging technologies or } \\
\text { concepts to be applied in } \\
\text { C\&D waste management }\end{array}$ & $\rightarrow$ & $\begin{array}{l}\text { 1. Integration of emerging technologies, } \\
\text { such as BIM and Big Data; 2. Circular } \\
\text { Economy as waste diversion approach }\end{array}$ \\
\hline
\end{tabular}

Fig.8. Framework linking current research topics to future research directions

Comparing the framework in Fig. 8 and the trend analysis initiated by Yuan and Shen (2011), more promising future research directions can be summarized below:

- A benchmarked or comprehensive quantification system needs to be developed to accurately predict the waste generation in the project design or planning stage. Multiple factors need to be considered in waste estimate, including but not limited to building structural type, project location, and product system, etc. Benchmarking WGR is still a research gap in need of more research together with benchmarking the environmental impacts (e.g., carbon footprint) associated with C\&D wastes; 
- A more comprehensive decision-making system can be incorporated in the project planning and design stage. LCA would be implemented in the design stage by considering multiple factors such as waste treatment methods and waste sorting strategies;

- Investigations of waste generation in developing economies expected by Yuan and Shen (2011) have been carried out in China (Ding and Xiao, 2014; Zheng et al., 2017), Vietnam (Lockrey et al., 2018), and Malaysia (Mahayuddin and Pereira, 2014). The C\&D waste management practice needs to be compared between developing and developed economies to bridge the gap between them;

- Studies integrating different research domains could raise more attention and lead to significant contributions to the research community. Examples include prefabricated construction and waste reduction by Jaillon et al. (2009), BIM in waste estimate explored by Kim et al. (2017), applying GIS (i.e., Geographic Information System) to identify the potential C\&D waste illegal dumping areas (Seror and Portnov, 2018), and Big Data to study the C\&D waste practice (Lu et al., 2016). It is anticipated that these new information techniques plus the approach of circular economy would be more widely applied in the future research of $C \& D$ waste management throughout the project life cycle, from waste estimate in the design stage, monitoring in the construction or demolition stage, to the application of recycled products;

- Developing the body of knowledge in C\&D waste diversion climate and culture in the organizational, project, and industry level. Climate and culture in C\&D waste diversion are reflected in individuals’ perceptions, attitudes, and behaviors. Dimensions for measuring the climate and culture can be developed, similar to what Chen and Jin (2013) performed for construction safety. More demographic or subgroup factors, such as practitioners' professions stressed by Jin et al. (2017), can be studied to build the framework of C\&D waste diversion climate and culture. 


\section{Conclusion}

This review-based study in C\&D waste management adopted a holistic approach incorporating bibiometric literature search, scientometric analysis, and in-depth qualitative discussion. A total of 370 journal articles published since 2009 were selected as the literature sample. The generally increasing trend of studies in C\&D waste management was confirmed according to the yearly number of publications. The scientometric analysis revealed the following findings:

- Influential journals that have been publishing research outputs in C\&D waste management include Waste Management, Resources, Conservation, and Recycling, and Journal of Cleaner Production.

- Keyword analysis and science mapping identified main clusters of keywords as waste treatment methods (e.g., recycling), sustainability impact (e.g., carbon footprint), technical properties of recycled products, waste management approach (e.g., life cycle assessment), quantification of waste generation, and newly emerging technologies (e.g., BIM);

- Co-author analysis identified productive and influential analysis of scholars in the research community of C\&D waste management. The scholar of Yuan H. was identified with the highest number of publications and with the highest average citation per personal publication;

- Articles receiving the highest citations since 2009 were identified and main research topics of these influential articles were discussed, such as prefabricated construction and BIM in enhancing waste reduction;

- Countries that have been active in the research of $C \& D$ waste management were identified and discussed. More C\&D waste management research has been conducted in developing economies, such as China, Vietnam, Thailand, and Brazil. 
Following the scientometric analysis, a follow-up qualitative analysis was performed to summarize the mainstream research topics in $C \& D$ waste management, and simultaneously to identify the research gaps and propose future research directions. The main research topics were categorized into practice and research of properties of products containing recycled contents, quantification methods to estimate waste generation, $C \& D$ waste diversion practice in developing countries, and design for waste diversion. Gaps identified from existing studies included the difference of C\&D waste diversion practice between developing and developed economies, standardized performance measurements for $C \& D$ waste management, human factors, as well as applications of emerging technologies and concepts (e.g., BIM, Big Data, and Circular Economy). The study further contributes to the domain of C\&D waste management for proposing the framework and directions for near-future research, including:

- Benchmarking of waste generation rate and decision making in the project planning and design stages for waste management;

- A comprehensive evaluation of the performance of C\&D waste management from the life cycle assessment perspective;

- Application of recycled contents in prefabricated building components;

- Comparison of C\&D waste management practice between developing and developed economies;

- Building the body of knowledge of Circular Economy (as an emerging approach and new business model) for its proper application in C\&D waste management;

- Integration of newly emerging technologies in waste management, including BIM, GIS, Big Data, and prefabricated construction;

- Continuing development of the human-factor-related framework in C\&D waste management, such as waste diversion climate and culture. 
This review-based study in C\&D waste management was limited to its literature sample.

Firstly, it only recruited journal articles and was more focusing on the academic research movement of C\&D waste management. Other publication sources, including trade magazines or conference proceedings were excluded. There would be a further need to identify the uncertainty between the latest industry practice and the scholarly research. Secondly, the literature sample only included articles published in English. Research or practical outputs in other languages were not reported in this study.

\section{Acknowledgement}

This study was supported by the National Natural Science Foundation of China (No.: 71573216) and the Sichuan Science and Technology Program (No.: 2017ZR0150).

\section{References}

Abanda, F.H., Tah, J.H.M., Cheung, F.K.T., 2013. Mathematical modelling of embodied energy, greenhouse gases, waste, time-cost parameters of building projects: A review. Build. Environ. 59, 23-37.

Aghaei Chadegani, A., Salehi, H., Md Yunus, M.M., Farhadi, H., Fooladi, M., Farhadi, M., Ale Ebrahim, N., 2013. A comparison between two main academic literature collections: Web of science and scopus databases. Asian Soc. Sci. 9(5), 18-26.

Ajayi, S.O., Oyedele, L.O., 2017. Policy imperatives for diverting construction waste from landfill: Experts' recommendations for UK policy expansion. J. Clean. Prod. 147, 57-65.

Ajayi, S.O., Oyedele, L.O., Akinade, O.O., Bilal, M., Alaka, H.A., Owolabi, H.A., 2017a. Optimising material procurement for construction waste minimization: An exploration of success factors. Sustain. Mater. Technol. 11, 38-46.

Ajayi, S.O., Oyedele, L.O., Bilal, M., Akinade, O.O., Alaka, H.A., Owolabi, H.A., 2017b. Critical management practices influencing on-site waste minimization in construction projects. Waste Manage. 59, 330-339.

Ajayi, S.O., Oyedele, L.O., Bilal, M., Akinade, O.O., Alaka, H.A., Owolabi, H.A., Kadiri, K.O., 2015. Waste effectiveness of the construction industry: Understanding the impediments and requisites for improvements. Resour. Conserv. Recycl. 102, 101-112.

Akinade, O.O., Oyedele, L.O., Ajayi, S.O., Bilal, M., Alaka, H.A., Owolabi, H.A., Arawomo, O.O., 2018. Designing out construction waste using BIM technology: Stakeholders' expectations for industry deployment. J. Clean. Prod. 180, 375-385.

Al-Bayati, H.K.A., Tighe, S.L., Achebe, J., 2018. Influence of recycled concrete aggregate on volumetric properties of hot mix asphalt. Resour. Conserv. Recycl. 130, 200-214.

Arm, M., Wik, O., Engelsen, C.J., Erlandsson, M., Hjelmar, O., Wahlström, M., 2017. How Does the European Recovery Target for Construction \& Demolition Waste Affect Resource Management? Waste Biomass Valoris. 8(5), 1491-1504. 
Bakshan, A., Srour, I., Chehab, G., El-Fadel, M., Karaziwan, J., 2017. Behavioral determinants towards enhancing construction waste management: A Bayesian Network analysis. Resour. Conserv. Recycl. 117, 274-284.

Baldwin, A., Poon, C.S., Shen, L.Y., Austin, S., Wong, I., 2009. Designing out waste in highrise residential buildings: Analysis of precasting methods and traditional construction. Renew. Energy 34(9), 2067-2073.

Begum, R.A., Siwar, C., Pereira, J.J., Jaafar, A.H., 2009. Attitude and behavioral factors in waste management in the construction industry of Malaysia. Resour. Conserv. Recycl. 53(6), 321-328.

Bilal, M., Oyedele, L.O., Qadir, J., Munir, K., Akinade, O.O., Ajayi, S.O., Alaka, H.A., Owolabi, H.A., 2015. Analysis of critical features and evaluation of BIM software: towards a plug-in for construction waste minimization using big data. Int. J. Sustainable Build. Tech. Urban Dev. 6(4), 211-228.

Bovea, M.D., Powell, J.C., 2016. Developments in life cycle assessment applied to evaluate the environmental performance of construction and demolition wastes. Waste Manage. 50, 151-172.

Brasileiro, L.L., Matos, J.M.E., 2015. Literature review: Reuse of construction and demolition waste in the construction industry. Ceramica 61(358), 178-189.

Butler, L., Visser, M.S., 2006. Extending citation analysis to non-source items. Scientometrics 66(2), 327-343.

C\&D Waste Management Guide, 2016. Minimizing construction \& demolition waste. Department of Health, Office of Solid Waste Management, Honolulu, HI.

Cabrera-Covarrubias, F.G., Gómez-Soberón, J.M., Almaral-Sánchez, J.L., Corral-Higuera, R., Gómez-Soberón, M.C., 2017. Implementation of interaction diagram of the properties in fresh for mortars with ceramic aggregates. Period. Polytech. Civ. Eng. 61(2), 335-340.

Chau, C.K., Hui, W.K., Ng, W.Y., Powell, G., 2012. Assessment of CO 2 emissions reduction in high-rise concrete office buildings using different material use options. Resour. Conserv. Recycl. 61, 22-34.

Chen, Q., Jin, R., 2015. A comparison of subgroup construction workers' perceptions of a safety program. Saf. Sci. 74, 15-26.

Chen, X., Lu, W., 2017. Identifying factors influencing demolition waste generation in Hong Kong. J. Clean. Prod. 141, 799-811.

Chen, Z., Xu, J., Chen, Y., Lui, E.M., 2016. Recycling and reuse of construction and demolition waste in concrete-filled steel tubes: A review. Constr Build Mater 126, 641660.

Cheng, J.C.P., Ma, L.Y.H., 2013. A BIM-based system for demolition and renovation waste estimation and planning. Waste Manage. 33(6), 1539-1551.

Cheng, K.L., Hsu, S.C., Li, W.M., Ma, H.W., 2018. Quantifying potential anthropogenic resources of buildings through hot spot analysis. Resour. Conserv. Recycl. 133, 10-20.

Coelho, A., Brito, J.D., 2013. Environmental analysis of a construction and demolition waste recycling plant in Portugal - Part I: Energy consumption and CO2 emissions. Waste Manage. 33(5), 1258-1267.

Coelho, A., De Brito, J., 2013. Economic viability analysis of a construction and demolition waste recycling plant in Portugal - Part II: Economic sensitivity analysis. J. Clean. Prod. 39, 329-337.

da Rocha, C.G., Sattler, M.A., 2009. A discussion on the reuse of building components in Brazil: An analysis of major social, economical and legal factors. Resour. Conserv. Recycl. 54(2), 104-112. 
Dahlbo, H., Bachér, J., Lähtinen, K., Jouttijärvi, T., Suoheimo, P., Mattila, T., Sironen, S., Myllymaa, T., Saramäki, K., 2015. Construction and demolition waste management - A holistic evaluation of environmental performance. J. Clean. Prod. 107, 333-341.

de Magalhães, R.F., Danilevicz, Â.D.M.F., Saurin, T.A., 2017. Reducing construction waste: A study of urban infrastructure projects. Waste Manage. 67, 265-277.

Ding, T., Xiao, J., 2014. Estimation of building-related construction and demolition waste in Shanghai. Waste Manage. 34(11), 2327-2334.

Ding, Z., Wang, Y., Zou, P.X.W., 2016. An agent based environmental impact assessment of building demolition waste management: Conventional versus green management. J. Clean. Prod. 133, 1136-1153.

Ding, Z., Zhu, M., Tam, V.W.Y., Yi, G., Tran, C.N.N., 2018. A system dynamics-based environmental benefit assessment model of construction waste reduction management at the design and construction stages. J. Clean. Prod. 176, 676-692.

Doan, D.T., Chinda, T., 2016. Modeling construction and demolition waste recycling program in Bangkok: Benefit and cost analysis. J Constr Eng Manage 142(12).

Dong, T.T.T., Lee, B.K., 2009. Analysis of potential RDF resources from solid waste and their energy values in the largest industrial city of Korea. Waste Manage. 29(5), 17251731.

Duan, H., Li, J., 2016. Construction and demolition waste management: China's lessons. Waste Manage. Res. 34(5), 397-398.

Esa, M.R., Halog, A., Rigamonti, L., 2017a. Developing strategies for managing construction and demolition wastes in Malaysia based on the concept of circular economy. J. Mater. Cycles Waste Manage. 19(3), 1144-1154.

Esa, M.R., Halog, A., Rigamonti, L., 2017b. Strategies for minimizing construction and demolition wastes in Malaysia. Resour. Conserv. Recycl. 120, 219-229.

European Commission, 2011. Supporting Environmentally Sound Decisions for 777 Construction and Demolition (C\&D) Waste Management. EUR 24918 EN - 2011.

Evangelista, L., De Brito, J., 2014. Concrete with fine recycled aggregates: A review. Eur. J. Environ. Civ. Eng. 18(2), 129-172.

Fagnani, E., Guimarães, J.R., 2017. Waste management plan for higher education institutions in developing countries: The Continuous Improvement Cycle model. J. Clean. Prod. 147, 108-118.

Ferreira-Sánchez, A., Marrero, M., 2017. Waste management of emergency construction work. Case study: 40 dwellings in Seville (Spain). Open Construct. Build. Technol. J. 11, 110-123.

Ghisellini, P., Cialani, C., Ulgiati, S., 2016. A review on circular economy: The expected transition to a balanced interplay of environmental and economic systems. J. Clean. Prod. 114, 11-32.

Ghose, A., Pizzol, M., McLaren, S.J., 2017. Consequential LCA modelling of building refurbishment in New Zealand- an evaluation of resource and waste management scenarios. J. Clean. Prod. 165, 119-133.

Hammersley, M., 2001. On 'systematic' reviews of research literatures: A 'narrative' response to Evans \& Benefield. Br. Educ. Res. J. 27(5), 542-554.

Hao, X., Larney, F.J., 2017. Greenhouse gas emissions during co-composting of cattle feedlot manure with construction and demolition (C\&D) waste. Front. Environ. Sci. Eng. 11(3).

He, Q., Wang, G., Luo, L., Shi, Q., Xie, J., Meng, X., 2017. Mapping the managerial areas of Building Information Modeling (BIM) using scientometric analysis. International Journal of Project Management 35(4), 670-685.

Hong, J., Shen, G.Q., Li, Z., Zhang, B., Zhang, W., 2018. Barriers to promoting prefabricated construction in China: A cost-benefit analysis. J. Clean. Prod. 172, 649-660. 
Hong, J., Shen, G.Q., Mao, C., Li, Z., Li, K., 2016. Life-cycle energy analysis of prefabricated building components: An input-output-based hybrid model. J. Clean. Prod. 112, 2198-2207.

Hosseini, M.R., Martek, I., Zavadskas, E.K., Aibinu, A.A., Arashpour, M., Chileshe, N., 2018. Critical evaluation of off-site construction research: A Scientometric analysis. Autom Constr 87, 235-247.

Huang, B., Wang, X., Kua, H., Geng, Y., Bleischwitz, R., Ren, J., 2018. Construction and demolition waste management in China through the 3R principle. Resour. Conserv. Recycl. 129, 36-44.

Jaillon, L., Poon, C.S., Chiang, Y.H., 2009. Quantifying the waste reduction potential of using prefabrication in building construction in Hong Kong. Waste Manage. 29(1), 309320.

Japanese Industrial Standards, 2005. Recycled concrete using recycled aggregate class H: JIS A 5021. Japanese Standards Association, Tokyo, Japan.

Jelić, I., Šljivić-Ivanović, M., Dimović, S., Antonijević, D., Jović, M., Mirković, M., Smičiklas, I., 2018. The applicability of construction and demolition waste components for radionuclide sorption. J. Clean. Prod. 171, 322-332.

Jin, R., Chen, Q., 2015. Investigation of Concrete Recycling in the U.S. Construction Industry, International Conference on Sustainable Design, Engineering and Construction, ICSDEC 2015. Elsevier Ltd, pp. 894-901.

Jin, R., Chen, Q., 2018. An Empirical Study of Concrete Recycling in the U.S.: From Legislation to Practice. J Constr Eng Manage in Press, DOI: 10.1061/(ASCE)CO.19437862.0001630.

Jin, R., Gao, S., Cheshmehzangi, A., Aboagye-Nimo, E., 2018. A holistic review of off-site construction literature published between 2008 and 2018. J. Clean. Prod. 202, 1202-1219.

Jin, R., Li, B., Zhou, T., Wanatowski, D., Piroozfar, P., 2017. An empirical study of perceptions towards construction and demolition waste recycling and reuse in China. Resour. Conserv. Recycl. 126, 86-98.

Jones, D.L., Chesworth, S., Khalid, M., Iqbal, Z., 2009. Assessing the addition of mineral processing waste to green waste-derived compost: An agronomic, environmental and economic appraisal. Bioresour. Technol. 100(2), 770-777.

Ke, Y., Wang, S., Chan, A.P.C., Cheung, E., 2009. Research trend of public-private partnership in construction journals. J Constr Eng Manage 135(10), 1076-1086.

Kim, Y.C., Hong, W.H., Park, J.W., Cha, G.W., 2017. An estimation framework for building information modeling (BIM)-based demolition waste by type. Waste Manage. Res. 35(12), 1285-1295.

Kleemann, F., Lederer, J., Aschenbrenner, P., Rechberger, H., Fellner, J., 2016. A method for determining buildings material composition prior to demolition. Build Res Inf 44(1), 5162.

Kleemann, F., Lehner, H., Szczypińska, A., Lederer, J., Fellner, J., 2017. Using change detection data to assess amount and composition of demolition waste from buildings in Vienna. Resour. Conserv. Recycl. 123, 37-46.

Kofoworola, O.F., Gheewala, S.H., 2009. Estimation of construction waste generation and management in Thailand. Waste Manage. 29(2), 731-738.

Kucukvar, M., Egilmez, G., Tatari, O., 2014. Evaluating environmental impacts of alternative construction waste management approaches using supply-chain-linked life-cycle analysis. Waste Manage. Res. 32(6), 500-508.

Lachimpadi, S.K., Pereira, J.J., Taha, M.R., Mokhtar, M., 2012. Construction waste minimisation comparing conventional and precast construction (Mixed System and IBS) 
methods in high-rise buildings: A Malaysia case study. Resour. Conserv. Recycl. 68, 96103.

Laquatra, J., Pierce, M., 2009. Taking construction site waste management to the next level. J. Green Build. 4(4), 29-32.

Li, J., Zuo, J., Cai, H., Zillante, G., 2018a. Construction waste reduction behavior of contractor employees: An extended theory of planned behavior model approach. J. Clean. Prod. 172, 1399-1408.

Li, N., Han, R., Lu, X., 2018b. Bibliometric analysis of research trends on solid waste reuse and recycling during 1992-2016. Resour. Conserv. Recycl. 130, 109-117.

Li, Y., Zhang, X., 2013. Web-based construction waste estimation system for building construction projects. Autom Constr 35, 142-156.

Li, Z., Shen, G.Q., Alshawi, M., 2014. Measuring the impact of prefabrication on construction waste reduction: An empirical study in China. Resour. Conserv. Recycl. 91, 27-39.

Ling, F.Y.Y., Nguyen, D.S.A., 2013. Strategies for construction waste management in Ho Chi Minh City, Vietnam. Built Environ. Proj. Asset Manage. 3(1), 141-156.

Llatas, C., 2011. A model for quantifying construction waste in projects according to the European waste list. Waste Manage. 31(6), 1261-1276.

Llatas, C., Osmani, M., 2016. Development and validation of a building design waste reduction model. Waste Manage. 56, 318-336.

Lockrey, S., Nguyen, H., Crossin, E., Verghese, K., 2016. Recycling the construction and demolition waste in Vietnam: opportunities and challenges in practice. J. Clean. Prod. 133, 757-766.

Lockrey, S., Verghese, K., Crossin, E., Nguyen, H., 2018. Concrete recycling life cycle flows and performance from construction and demolition waste in Hanoi. J. Clean. Prod. 179, 593-604.

Lu, M., Lau, S.C., Poon, C.S., 2009. Simulation approach to evaluating cost efficiency of selective demolition practices: Case of Hong Kong's Kai Tak Airport demolition. J Constr Eng Manage 135(6), 448-457.

Lu, W., Chen, X., Ho, D.C.W., Wang, H., 2016. Analysis of the construction waste management performance in Hong Kong: The public and private sectors compared using big data. J. Clean. Prod. 112, 521-531.

Lu, W., Chen, X., Peng, Y., Shen, L., 2015. Benchmarking construction waste management performance using big data. Resour. Conserv. Recycl. 105, 49-58.

Lu, W., Yuan, H., 2010. Exploring critical success factors for waste management in construction projects of China. Resour. Conserv. Recycl. 55(2), 201-208.

Lu, W., Yuan, H., 2011. A framework for understanding waste management studies in construction. Waste Manage. 31(6), 1252-1260.

Lu, W., Yuan, H., Li, J., Hao, J.J.L., Mi, X., Ding, Z., 2011. An empirical investigation of construction and demolition waste generation rates in Shenzhen city, South China. Waste Manage. 31(4), 680-687.

Mah, C.M., Fujiwara, T., Ho, C.S., 2016. Construction and demolition waste generation rates for high-rise buildings in Malaysia. Waste Manage. Res. 34(12), 1224-1230.

Mah, C.M., Fujiwara, T., Ho, C.S., 2017. Concrete waste management decision analysis based on life cycle assessment. Chem. Eng. Trans. 56, 25-30.

Mahayuddin, S.A., Pereira, J.J., 2014. Generation and management of waste in residential construction. Malays. Constr. Res. J. 14(1), 17-29.

Mahpour, A., 2018. Prioritizing barriers to adopt circular economy in construction and demolition waste management. Resour. Conserv. Recycl. 134, 216-227. 
María, D.B., Samantha, E.C.S., Irma, M., Claudia, C.N., Mónica, E.U., Valeria, I.F., 2016. Application of the Life Cycle Assessment methodology to evaluate the environmental performance of waste management systems in Iberoamerica. Rev. Int. Contam. Ambient. 32(EspecialResiduosSolidos), 23-46.

Marrero, M., Puerto, M., Rivero-Camacho, C., Freire-Guerrero, A., Solís-Guzmán, J., 2017. Assessing the economic impact and ecological footprint of construction and demolition waste during the urbanization of rural land. Resour. Conserv. Recycl. 117, 160-174.

Martínez-Aires, M.D., López-Alonso, M., Martínez-Rojas, M., 2018. Building information modeling and safety management: A systematic review. Saf. Sci. 101, 11-18.

Mastrucci, A., Marvuglia, A., Popovici, E., Leopold, U., Benetto, E., 2017. Geospatial characterization of building material stocks for the life cycle assessment of end-of-life scenarios at the urban scale. Resour. Conserv. Recycl. 123, 54-66.

Masudi, A.F., Che Hassan, C.R., Mahmood, N.Z., Mokhtar, S.N., Sulaiman, N.M., 2012. Waste quantification models for estimation of construction and demolition waste generation: A review. Int. J. Global Environ. Iss. 12(2-4), 269-281.

Matias, D., De Brito, J., Rosa, A., Pedro, D., 2013. Mechanical properties of concrete produced with recycled coarse aggregates - Influence of the use of superplasticizers. Constr Build Mater 44, 101-109.

Menegaki, M., Damigos, D., 2018. A review on current situation and challenges of construction and demolition waste management. Curr. Opin. Green Sustain. Chem. 13, 815.

Meng, Y., Ling, T.C., Mo, K.H., 2018. Recycling of wastes for value-added applications in concrete blocks: An overview. Resour. Conserv. Recycl. 138, 298-312.

Mercader-Moyano, P., Ramírez-De-Arellano-Agudo, A., 2013. Selective classification and quantification model of $C \& D$ waste from material resources consumed in residential building construction. Waste Manage. Res. 31(5), 458-474.

Miatto, A., Schandl, H., Wiedenhofer, D., Krausmann, F., Tanikawa, H., 2017. Modeling material flows and stocks of the road network in the United States 1905-2015. Resour. Conserv. Recycl. 127, 168-178.

Molenaar, K.R., Park, J.I., Washington, S., 2009. Framework for measuring corporate safety culture and its impact on construction safety performance. J Constr Eng Manage 135(6), 488-496.

Naustdalslid, J., 2014. Circular economy in China - The environmental dimension of the harmonious society. Int. J. Sustainable Dev. World Ecol. 21(4), 303-313.

Nikmehr, B., Reza Hosseini, M., Rameezdeen, R., Chileshe, N., Ghoddousi, P., Arashpour, M., 2017. An integrated model for factors affecting construction and demolition waste management in Iran. Eng. Constr. Archit. Manage. 24(6), 1246-1268.

Oladiran, O.J., 2009. Innovative waste management through the use of waste management plans on construction projects in Nigeria. Arch. Eng. Des. 5(3), 165-176.

Oliveira Neto, R., Gastineau, P., Cazacliu, B.G., Le Guen, L., Paranhos, R.S., Petter, C.O., 2017. An economic analysis of the processing technologies in CDW recycling platforms. Waste Manage. 60, 277-289.

Oraee, M., Hosseini, M.R., Papadonikolaki, E., Palliyaguru, R., Arashpour, M., 2017. Collaboration in BIM-based construction networks: A bibliometric-qualitative literature review. International Journal of Project Management 35(7), 1288-1301.

Parisi Kern, A., Ferreira Dias, M., Piva Kulakowski, M., Paulo Gomes, L., 2015. Waste generated in high-rise buildings construction: A quantification model based on statistical multiple regression. Waste Manage. 39, 35-44. 
Park, J.Y., Nagy, Z., 2018. Comprehensive analysis of the relationship between thermal comfort and building control research - A data-driven literature review. Renewable Sustainable Energy Rev 82, 2664-2679.

Pattnaik, S., Reddy, M.V., 2010. Assessment of Municipal Solid Waste management in Puducherry (Pondicherry), India. Resour. Conserv. Recycl. 54(8), 512-520.

Poulikakos, L.D., Papadaskalopoulou, C., Hofko, B., Gschösser, F., Cannone Falchetto, A., Bueno, M., Arraigada, M., Sousa, J., Ruiz, R., Petit, C., Loizidou, M., Partl, M.N., 2017. Harvesting the unexplored potential of European waste materials for road construction. Resour. Conserv. Recycl. 116, 32-44.

Puskás, A., Corbu, O., Szilágyi, H., Moga, L.M., 2014. Construction waste disposal practices: The recycling and recovery of waste. WIT Trans. Ecol. Environ. 191, 1313-1321.

Rahimi, M., Ghezavati, V., 2018. Sustainable multi-period reverse logistics network design and planning under uncertainty utilizing conditional value at risk $(\mathrm{CVaR})$ for recycling construction and demolition waste. J. Clean. Prod. 172, 1567-1581.

Ren, J., Manzardo, A., Toniolo, S., Scipioni, A., 2013. Sustainability of hydrogen supply chain. Part I: Identification of critical criteria and cause-effect analysis for enhancing the sustainability using DEMATEL. Int J Hydrogen Energy 38(33), 14159-14171.

Revathi, P., Selvi, R.S., Velin, S.S., 2013. Investigations on Fresh and Hardened Properties of Recycled Aggregate Self Compacting Concrete. J. Inst. Eng. Ser. A 94(3), 179-185.

Rodríguez-Robles, D., García-González, J., Juan-Valdés, A., Morán-Del Pozo, J.M., GuerraRomero, M.I., 2015. Overview regarding construction and demolition waste in Spain. Environ. Technol. 36(23), 3060-3070.

Rose, C.M., Stegemann, J.A., 2018. From waste management to component management in the construction industry. Sustainability 10(1).

Roussat, N., Dujet, C., Méhu, J., 2009. Choosing a sustainable demolition waste management strategy using multicriteria decision analysis. Waste Manage. 29(1), 12-20.

Sáez, P.V., Porras-Amores, C., Del Río Merino, M., 2015. New quantification proposal for construction waste generation in new residential constructions. J. Clean. Prod. 102, 58-65.

Seror, N., Portnov, B.A., 2018. Identifying areas under potential risk of illegal construction and demolition waste dumping using GIS tools. Waste Manage.

Shen, L.Y., Tam, V.W.Y., Tam, C.M., Drew, D., 2004. Mapping approach for examining waste management on construction sites. J Constr Eng Manage 130(4), 472-481.

Sim, J., Park, C., 2011. Compressive strength and resistance to chloride ion penetration and carbonation of recycled aggregate concrete with varying amount of fly ash and fine recycled aggregate. Waste Manage. 31(11), 2352-2360.

Song, J., Zhang, H., Dong, W., 2016. A review of emerging trends in global PPP research: analysis and visualization. Scientometrics 107(3), 1111-1147.

Sou, W.I., Chu, A., Chiueh, P.T., 2016. Sustainability assessment and prioritisation of bottom ash management in Macao. Waste Manage. Res. 34(12), 1275-1282.

Staley, B.F., Barlaz, M.A., 2009. Composition of municipal solid waste in the united states and implications for carbon sequestration and methane yield. J. Environ. Eng. 135(10), 901-909.

Su, H.N., Lee, P.C., 2010. Mapping knowledge structure by keyword co-occurrence: A first look at journal papers in Technology Foresight. Scientometrics 85(1), 65-79.

Tam, V.W.Y., 2009. Comparing the implementation of concrete recycling in the Australian and Japanese construction industries. J. Clean. Prod. 17(7), 688-702.

Tang, L., Shen, Q., Cheng, E.W.L., 2010. A review of studies on Public-Private Partnership projects in the construction industry. Int. J. Proj. Manage. 28(7), 683-694. 
Umar, U.A., Shafiq, N., Malakahmad, A., Nuruddin, M.F., Khamidi, M.F., 2017. A review on adoption of novel techniques in construction waste management and policy. J. Mater. Cycles Waste Manage. 19(4), 1361-1373.

van Eck, N.J., Waltman, L., 2010. Software survey: VOSviewer, a computer program for bibliometric mapping. Scientometrics 84(2), 523-538.

Van Eck, N.J., Waltman, L., 2014. Visualizing bibliometric networks. . In Y. Ding, R. Rousseau, \& D. Wolfram (Eds.), Measuring scholarly impact: Methods and practice, 285320). .

Wang, J., Yuan, H., Kang, X., Lu, W., 2010. Critical success factors for on-site sorting of construction waste: A china study. Resour. Conserv. Recycl. 54(11), 931-936.

Won, J., Cheng, J.C.P., 2017. Identifying potential opportunities of building information modeling for construction and demolition waste management and minimization. Autom Constr 79, 3-18.

Wu, Z., Yu, A.T.W., Shen, L., 2017. Investigating the determinants of contractor's construction and demolition waste management behavior in Mainland China. Waste Manage. 60, 290-300.

Xu, Y., Zeng, J., Chen, W., Jin, R., Li, B., Pan, Z., 2018. A holistic review of cement composites reinforced with graphene oxide. Constr Build Mater 171, 291-302.

Xue, J., Yuan, H., Shi, B., 2017. Impact of Contextual Variables on Effectiveness of Partnership Governance Mechanisms in Megaprojects: Case of Guanxi. J Manage Eng 33(1).

Yuan, H., 2013. A SWOT analysis of successful construction waste management. J. Clean. Prod. 39, 1-8.

Yuan, H., 2017. Barriers and countermeasures for managing construction and demolition waste: A case of Shenzhen in China. J. Clean. Prod. 157, 84-93.

Yuan, H., Chini, A.R., Lu, Y., Shen, L., 2012. A dynamic model for assessing the effects of management strategies on the reduction of construction and demolition waste. Waste Manage. 32(3), 521-531.

Yuan, H., Shen, L., 2011. Trend of the research on construction and demolition waste management. Waste Manage. 31(4), 670-679.

Yuan, H., Shen, L., Wang, J., 2011a. Major obstacles to improving the performance of waste management in China's construction industry. Facilities 29(5), 224-242.

Yuan, H., Wang, J., 2014. A system dynamics model for determining the waste disposal charging fee in construction. Eur J Oper Res 237(3), 988-996.

Yuan, H.P., Shen, L.Y., Hao, J.J.L., Lu, W.S., 2011b. A model for cost-benefit analysis of construction and demolition waste management throughout the waste chain. Resour. Conserv. Recycl. 55(6), 604-612.

Yusuf, N., Kamaruddeen, A.M., Bahaudin, A.Y., 2016. Moderating effect of government policy on the relationship between organizational structure and construction waste management. Revista Tecnica de la Facultad de Ingenieria Universidad del Zulia 39(1), 88-100.

Zambrana-Vasquez, D., Zabalza-Bribián, I., Jáñez, A., Aranda-Usón, A., 2016. Analysis of the environmental performance of life-cycle building waste management strategies in tertiary buildings. J. Clean. Prod. 130, 143-154.

Zanna, C.D., Fernandes, F., Gasparine, J.C., 2017. Solid construction waste management in large civil construction companies through use of specific software-case study. Acta Sci. Technol 39(2), 169-176.

Zega, C.J., Di Maio, Á.A., 2011. Use of recycled fine aggregate in concretes with durable requirements. Waste Manage. 31(11), 2336-2340. 
Zhang, X., Wu, Y., Shen, L., 2012. Application of low waste technologies for design and construction: A case study in Hong Kong. Renewable Sustainable Energy Rev 16(5), 2973-2979.

Zhao, X., 2017. A scientometric review of global BIM research: Analysis and visualization. Autom Constr 80, 37-47.

Zheng, L., Wu, H., Zhang, H., Duan, H., Wang, J., Jiang, W., Dong, B., Liu, G., Zuo, J., Song, Q., 2017. Characterizing the generation and flows of construction and demolition waste in China. Constr Build Mater 136, 405-413. 